Working Paper in Economics No. 813

\title{
All it takes is one: The effect of weakest-link and summation aggregation on public good provision under threshold uncertainty
}

Fredrik Carlsson, Claes Ek, and Andreas Lange

Department of Economics, November 2021 


\title{
All it takes is one: The effect of weakest-link and summation aggregation on public good provision under threshold uncertainty
}

\author{
Fredrik Carlsson ${ }^{\alpha}$, Claes $\mathrm{Ek}^{\beta}$, and Andreas Lange ${ }^{\gamma}$
}

October 2021

\begin{abstract}
We report experimental evidence on the voluntary provision of public goods under threshold uncertainty. By explicitly comparing two prominent technologies, summation and weakest link, we show that uncertainty is particularly detrimental to threshold attainment under weakest link, where low contributions by one subject cannot be compensated by others. In contrast, threshold uncertainty does not affect contributions under summation. We demonstrate non-binding pledges as one mechanism to improve chances of threshold attainment under both technologies, yet in particular under weakest link.
\end{abstract}

JEL: $\quad$ C91, H41, Q54

Keywords: public goods, threshold uncertainty, weakest link, coordination, experiment

\footnotetext{
${ }^{\alpha}$ University of Gothenburg; Email: fredrik.carlsson@economics.gu.se

${ }^{\beta}$ University of Gothenburg; Email: claes.ek@economics.gu.se

${ }^{\gamma}$ University of Hamburg, Email: andreas.lange@uni-hamburg.de
} 


\section{Introduction}

Economists have long highlighted the serious challenge that free-riding poses for the voluntary provision of public goods. In many settings, the level of the public good depends on the sum of voluntary contributions, which means that individuals may hope to free ride on the efforts by others (e.g., Zelmer, 2003). Yet, many public goods do not fit this framework of a summation technology. A prominent example is the weakest-link technology, where the level of the public good depends on the lowest individual contribution. Such weakest links are present, e.g., when protecting against terrorist attacks such as airplane hijacking or when fighting contagious diseases (Barrett, 2016; Caparròs and Finus, 2020a). In these settings, the outcome critically depends on the minimum level of contribution. The recent COVID-19 pandemic contains such features, as efforts by an individual country or region may not be sufficient to eradicate the disease, given that the likelihood of mutations depends on some host countries not having achieved a sufficient vaccination rate.

Yet, the link between effort (contributions) and the resulting provision level of the public good or the success of its provision is stochastic in many situations: the exact precautionary effort, e.g., the vaccination rate that prevents mutations or the security efforts that succeed in keeping terrorists out of high-security zones, might be unknown. That is, additional effort will only increase the chances of preventing an adverse event. Despite the importance of uncertain thresholds in weakest-link settings, no study has yet explored their behavioral consequences.

This paper reports experimental evidence on voluntary contributions to public goods with a threshold for the generation of benefits (or avoidance of a bad event). Our study is designed to explicitly investigate how the aggregation technology affects the likelihood of reaching the threshold. For this, we compare certain and uncertain thresholds within both a summation and a weakest-link setting. With summation, total contributions of the group need to exceed a specific threshold, while the threshold under weakest link is a minimum level of contribution that all group members have to achieve. 
Our paper contributes to diverse strands of the literature. Inspired by potential thresholds in the climate system (e.g., Steffen et al., 2018), a prominent discussion in the theoretical and experimental literature concerns how thresholds affect the provision of public goods under a summation technology (e.g., Barrett, 2013; Barrett and Dannenberg, 2012, 2014; Dannenberg et al., 2015). Thresholds provide a coordination mechanism, and may increase contributions. Yet according to Barrett and Dannenberg (2012, 2014), uncertainty about the threshold level substantially reduces the chances of successful coordination under summation. Intuitively, uncertainty about the threshold means that each individual is only able to impact the probability of threshold attainment at the margin. This increases the incentive to free ride compared with a known discontinuous threshold, making coordination equilibria more difficult to sustain. With this paper, we ask whether threshold uncertainty shows similar effects under a weakest-link technology.

Weakest-link structures add a coordination element to the voluntary provision of public goods: it is not worthwhile for an individual to contribute more than the smallest amount provided by another group member (Barrett, 2016). While this often gives rise to equilibria at contribution profiles other than the noncooperative outcome, the success of achieving successful coordination is far from guaranteed (Anderson et al., 2001; Caparròs and Finus, 2020a; Caparròs et al., 2020; Devetag and Ortmann, 2007), not least because a single individual making a mistake is strongly detrimental to the outcome and thus, subjects face substantial strategic uncertainty. The chances of successful coordination depend, among other things, on the communication that precedes contribution decisions, on the identity of contributors, and on heterogeneities among individuals (Barbieri and Malueg, 2019; Riechmann and Weimann, 2008; Chaudhuri et al., 2009; Engelmann and Normann, 2010; Brandts and Cooper, 2007; Hamman et al., 2007; Riedl et al., 2016; Harrison and Hirshleifer, 1989; Knez and Camerer, 1994; Lei et al., 2007). ${ }^{1}$ Non-binding contribution pledges are a limited form of communication. The effect of pledges on contributions is not clear-cut. On the one hand, pledges as simple numerical cheap talk had no

\footnotetext{
${ }^{1}$ Self-enforcing treaties is another approach to achieve successful coordination (Caparròs and Finus, 2020a,b).
} 
net effect on contributions is Bochet et al. (2006). On the other hand, Barrett and Dannenberg (2016) found positive effects of a pledge-review design where other players rate the pledges.

Our experimental design closely follows Barrett and Dannenberg $(2012,2014)$, who explored uncertain thresholds with a summation technology. As a baseline, we mimic their experimental treatments and then compare them with behavior in a corresponding weakest-link setting. Subjects interact in groups of 10 . Contributions generate payoffs that are linear in the sum of donations, yet failure to reach a contribution threshold induces a discrete lump sum loss. ${ }^{2}$ Threshold attainment under the summation technology requires the sum of contributions to reach the threshold. Under weakest link, all subjects have to reach the (appropriately scaled) threshold in order to avoid the adverse event. Anticipating that weakest-link settings might be more vulnerable to strategic uncertainty, we additionally explore the effect of non-binding pledges on threshold attainment.

Our experiment reveals the importance of the aggregation technology. First, we find under summation that uncertainty regarding the threshold does not affect contributions or the probability of threshold attainment. This is in stark contrast to Barrett and Dannenberg $(2012,2014)$, who identified a negative effect of threshold uncertainty. One explanation for the different results is that we find subjects largely adhering to their pledges, which was not the case in the earlier studies. Importantly, threshold uncertainty in the weakest-link setting shows quite different behavioral patterns. When the threshold level is certain, it provides a highly successful coordination device. In contrast, groups are almost guaranteed not to reach the threshold if the level is uncertain. Thus, we conclude that the role of strategic uncertainty is further enhanced when the threshold becomes uncertain, leading to considerably lower success rates. Compared with summation, this reflects the fact that threshold attainment hinges on all subjects

\footnotetext{
${ }^{2}$ The presence of both a linear and a threshold benefit is consistent with many real-world public goods, including climate mitigation and COVID-19 vaccination. For the latter, national vaccination programs limit the spread of existing viral variants to other countries (the linear component) while also reducing the risk that new variants will emerge (the threshold component).
} 
contributing a sufficient amount, such that high contributors are unable to compensate for low contributions by other group members.

In our experiment, the chances for threshold attainment in all treatments heavily hinge on subjects being able to announce non-binding pledges. A lack of pledges prior to contribution decisions particularly handicaps threshold attainment under weakest link. Exploring the mechanisms through which the possibility of pledges affects contributions, we find that the non-binding nature of the pledge appears to induce individuals to make larger contribution announcements. These promises are more likely to actually be kept if other people have made similar pledges..

The paper is structured as follows: Section 2 discusses the experimental design, before we provide some theoretical predictions in Section 3. Section 4 discusses our results in terms of threshold attainment, individual contribution decisions, and the role of pledges. Section 5 concludes.

\section{Experimental design}

The games played in our experiment are variants of the voluntary public good paradigm. In this section, we first provide general definitions and then describe our treatments and experimental protocols. Theoretical predictions are discussed in Section $3 .^{3}$

The games are played in groups of 10 players $i \in\{1, \ldots, 10\}$. Each player is endowed with 20 experimental tokens. The contribution to the common pool is denoted $q_{i} \in\{0,1, \ldots, 20\}$. Each player's opportunity cost of contributing is piecewise linear and convex, and given by

$$
C\left(q_{i}\right)=\left\{\begin{aligned}
c_{L} q_{i}, & \text { for } 0 \leq q_{i} \leq 10 \\
10 c_{L}+c_{H}\left(q_{i}-10\right), & \text { for } 11 \leq q_{i} \leq 20
\end{aligned}\right.
$$

where $c_{L}=€ 0.1$ and $c_{H}=€ 0.5 .^{4}$

\footnotetext{
3 The experimental design and analysis plan were formally registered with the American Economic Association's registry for randomized controlled trials (AEARCTR-0005175), and formally approved on December 11, 2019.

${ }^{4}$ In the experiment, the piecewise linear cost scheme was implemented as follows: Of each participant's 20 tokens, half were framed as belonging to a low-value "Account A" and the other half to a high-value "Account B." We hardcoded contributions to draw from account B only
} 
Contributions to the common pool have two effects: (i) they generate a publicgood return $r=€ 0.05$ to each group member per token contributed by any player, and (ii) they (weakly) increase the probability that the group reaches a threshold contribution level $\bar{Q}$, which is uniformly distributed on integers $\{a, a+1, \ldots, b-1, b\}$, with $b \geq a>0$. Total returns from contributing (after resolving the uncertainty in $\bar{Q}$ ) are

$$
r\left(\sum_{i=1}^{n} q_{i}\right)-f\left(q_{1}, \ldots, q_{n}, \bar{Q}\right) X
$$

where $f$ is a discontinuous function of the contributions and the threshold level, while $X=€ 15$ is a fixed cost of failing to reach the threshold.

Our treatments differ in the mapping of individual contributions into threshold attainment. Under a summation technology, the cost of $€ 15$ is paid by all players unless the group sum of contributions reaches at least $\bar{Q}$. Formally, $f=$ $I\left(\sum_{i=1}^{n} q_{i}<\bar{Q}\right)$, where $I$ is a binary indicator function. Under a weakest-link technology, the cost of $€ 15$ is paid unless all group members contribute at least $\bar{Q}$. That is, the contribution by the player with the smallest contribution needs to reach the threshold $f=I\left(q^{\text {min }}<\bar{Q}\right)$, where $q^{\text {min }}=\min _{i}\left(q_{i}\right)$.

Table 1 lists the six between-subject treatments included in the experiment. We use a 2-by-3 design that explores, first, the effect of technology, i.e., whether threshold attainment is based on summation or weakest-link aggregation. Second, we vary whether the location of the threshold is certain, or alternatively exhibits uncertainty in a broad ("uncertainty") or narrow range ("small uncertainty"). To make symmetric equilibria and per-person contributions as comparable as possible across technologies, weakest-link threshold ranges are obtained by dividing the corresponding ranges for the summation by $n=10$.

once account $\mathrm{A}$ had been exhausted. In addition to the endowment of tokens (worth $€ 6$ if retained) and any net earnings from the game, subjects were also given a fixed show-up fee of $€ 15$. 
Table 1. Experimental treatments

\begin{tabular}{llll}
\hline Treatments & Aggregation technology & Threshold support & $N$ \\
\hline T1: Sum, certainty & Summation: $\sum_{i=1}^{n} q_{i} \geq \bar{Q}$ & $\bar{Q}=150$ & 100 \\
T2: Sum, uncertainty & Summation: $\sum_{i=1}^{n} q_{i} \geq \bar{Q}$ & $\bar{Q} \in\{100, \ldots, 200\}$ & 100 \\
T3: Sum, small uncert. & Summation: $\sum_{i=1}^{n} q_{i} \geq \bar{Q}$ & $\bar{Q} \in\{140, \ldots, 160\}$ & 100 \\
T4: WL, certainty & Weakest link: $q_{i}^{\text {min }} \geq \bar{Q}$ & $\bar{Q}=15$ & 100 \\
T5: WL, uncertainty & Weakest link: $q_{i}^{\min } \geq \bar{Q}$ & $\bar{Q} \in\{10, \ldots, 20\}$ & 100 \\
T6: WL, small uncert. & Weakest link: $q_{i}^{\min } \geq \bar{Q}$ & $\bar{Q} \in\{14, \ldots, 16\}$ & 80 \\
\hline
\end{tabular}

The experiment was conducted at the laboratory of the Vienna Center for Experimental Economics, using the lab's associated subject pool of university students. A total of 29 experimental sessions were conducted, each with 20 subjects (two groups) belonging to the same treatment. ${ }^{5}$

The sessions progressed as follows. First, subjects were randomly assigned to one of the groups and acquainted with the game rules. ${ }^{6}$ Although there were no practice rounds, exhaustive examples and control questions were included to ensure that subjects understood the game. ${ }^{7}$ They were also informed that there were two rounds, one of which would be randomly chosen for payment at the end of the session. Subjects then played a first round of the game variant corresponding to their treatment. Importantly, this initial one-shot round was not followed by feedback of any kind.

Next, group composition was re-shuffled, with subjects informed that a second round would now take place among the new groups. Our main analysis is based on this second round. Immediately prior to it, subjects were asked to make a pair of non-binding announcements to the other members of their group. Subjects submitted, first, a proposal for how many tokens the group as a whole should contribute to the joint project, and second, a pledge to personally contribute some number of tokens in the coming round. All proposals and pledges made in a group were then displayed on screen to all members immediately before the subjects made the second round contribution decision.

\footnotetext{
${ }^{5}$ Our pre-registered initial plan included 120 subjects (12 groups) in each treatment. However, due to the onset of the COVID-19 pandemic, we were unable to conduct some of the planned sessions, leaving us with the sample sizes reported in Table 1.

${ }^{6}$ The experiment was programmed using the zTree software (Fischbacher, 2007).

${ }^{7}$ Instructions, examples, and control and survey questions are provided in Appendix A.
} 
After the conclusion of the second round, subjects filled out an end-of-session survey with questions on risk, time, and social preferences based on Falk et al. (2018), as well as demographic variables. ${ }^{8}$ We also asked subjects to (i) explain their reasoning behind pledging a certain contribution, (ii) rate how much they trusted the pledges of other group members, and (iii) judge whether the pledges and proposals of others made them change their own contribution level. Finally, subjects were informed of the outcome of both game rounds, including their own associated potential and actual earnings in each round.

\section{Theoretical predictions}

In Appendix B, we derive best responses and characterize associated Nash equilibria within each treatment. Some simplifying assumptions are applied: first, the analysis limits attention to symmetric equilibria. Second, players are assumed to be risk neutral throughout. Finally, we do not include the proposals and pledges made prior to the second round. Table 2 summarizes results obtained under these conditions.

\section{Table 2. Theoretical predictions by treatment}

\begin{tabular}{lcc}
\hline & \multicolumn{2}{c}{ Symmetric Nash equilibria (all $i$ ) } \\
\cline { 2 - 3 } Treatment & Non-cooperative & Coordination/cooperation \\
\hline T1. Summation, certainty & $q_{i}=0$ & $q_{i}=15$ \\
T2. Summation, uncertainty & $q_{i}=0$ & - \\
T3. Summation, small uncertainty & $q_{i}=0$ & $q_{i}=16$ \\
T4. Weakest link, certainty & $q_{i}=0$ & $q_{i}=15$ \\
T5. Weakest link, uncertainty & $q_{i}=0$ & $q_{i}=q \in\{10, \ldots, 20\}$ \\
T6. Weakest link, small uncertainty & $q_{i}=0$ & $q_{i}=q \in\{14, \ldots, 16\}$ \\
\hline
\end{tabular}

The non-cooperative symmetric equilibrium where each player has $q_{i}=0$ is supported in all treatments. However, the options for coordinating at higher contribution levels vary substantially across treatments. In summation under certainty (T1), there is a single symmetric equilibrium at the threshold (Isaac et al, 1989). This Pareto-dominant equilibrium disappears under large uncertainty (T2), as stressed by Barrett and Dannenberg (2012) and Barrett (2013). The

\footnotetext{
${ }^{8}$ We report the data on these survey questions in the Appendix Table C7. We also explored their impact on contribution decisions and pledges, finding that they do not have any explanatory power. Thus, we do not further discuss these preferences and variables in this paper.
} 
reason is that, as uncertainty is added, each player becomes less pivotal to threshold attainment since they can now only influence the probability that $\sum_{i=1}^{n} q_{i} \geq \bar{Q}$ at the margin. Under small uncertainty, however, the threshold support is small enough, and each player correspondingly pivotal enough, that a non-zero equilibrium survives (Barrett \& Dannenberg, 2014) at the upper bound of the support of $\bar{Q}$. Kotani et al. (2014) obtain a similar result for a game with binary contributions.

Under weakest link, there is again a coordination equilibrium at $q_{i}=15$ when the position of the threshold is known with certainty. However, unlike the summation case, introducing uncertainty creates a range of equilibria at every integer within the support of $\bar{Q}$. This is because the weakest-link structure leaves each player relatively pivotal to threshold attainment even in the presence of uncertainty. Thus, if every other player $j$ has chosen to contribute some $q_{j}=q$ in the interior of that support, then for the parameters used in our experiment, the remaining player $i$ will always prefer $q_{i}=q$ to $q_{i}<q$ (and will certainly not contribute $q_{i}>q_{j}$, since doing so would not change the outcome).

The main conclusion from Table 2 is that contributions in T2, where no "upper" equilibrium exists, should be lower than in all other treatments. Importantly, the effect of introducing large uncertainty differs substantially between the two aggregation technologies: cooperation collapses under summation but not under weakest link. Because all treatments except T2 involve multiple equilibria, further predictions will inevitably need to invoke some rule for equilibrium selection. For example, in our experiment, Pareto dominance consistently implies selecting the equilibrium with the highest contribution levels.

However, off-equilibrium behavior seems likely to prove highly important in the weakest-link treatments, where deviations from equilibrium play can strongly affect the outcome faced by all group members. Such deviations may be due to, e.g., mistakes (see Caparrós et al., 2020) or subjects attempting to coordinate on different equilibria. This strategic uncertainty may lead players to lower their contributions as the marginal effect of increased contributions on the probability of threshold attainment is reduced. Thus, Table 2 serves only as a benchmark but does not provide clear-cut predictions. 


\section{Results}

We first discuss threshold attainment and contribution decisions in the second round of the experiment in Sections 4.1 and 4.2, respectively. That is, we focus first on contributions following non-binding contribution pledges and proposals on how many tokens the group should contribute. Here, our results under the summation technology are directly comparable to Barrett and Dannenberg (2012, 2014). In Section 4.3, we explore the mechanisms through which pledges affect contribution decisions. We investigate how individual pledges compare to decisions in the initial game round, and also whether subjects follow through with their pledges or renege on them.

\subsection{Threshold attainment}

We begin by examining threshold attainment across treatments. Rather than reporting observed success rates among the subject groups, we calculate each group's probability of reaching the threshold according to the cumulative distribution of $\bar{Q}$. Figure 1 reports the distribution of the resulting probabilities for each of the six treatments. For each treatment, we also report the average probability $(\bar{P})$ among subject groups. In the certainty treatments, this average equals the observed success rates. The probabilities underlying Figure 1 are also given in Table $\mathrm{C} 1$ of Appendix $\mathrm{C}$.

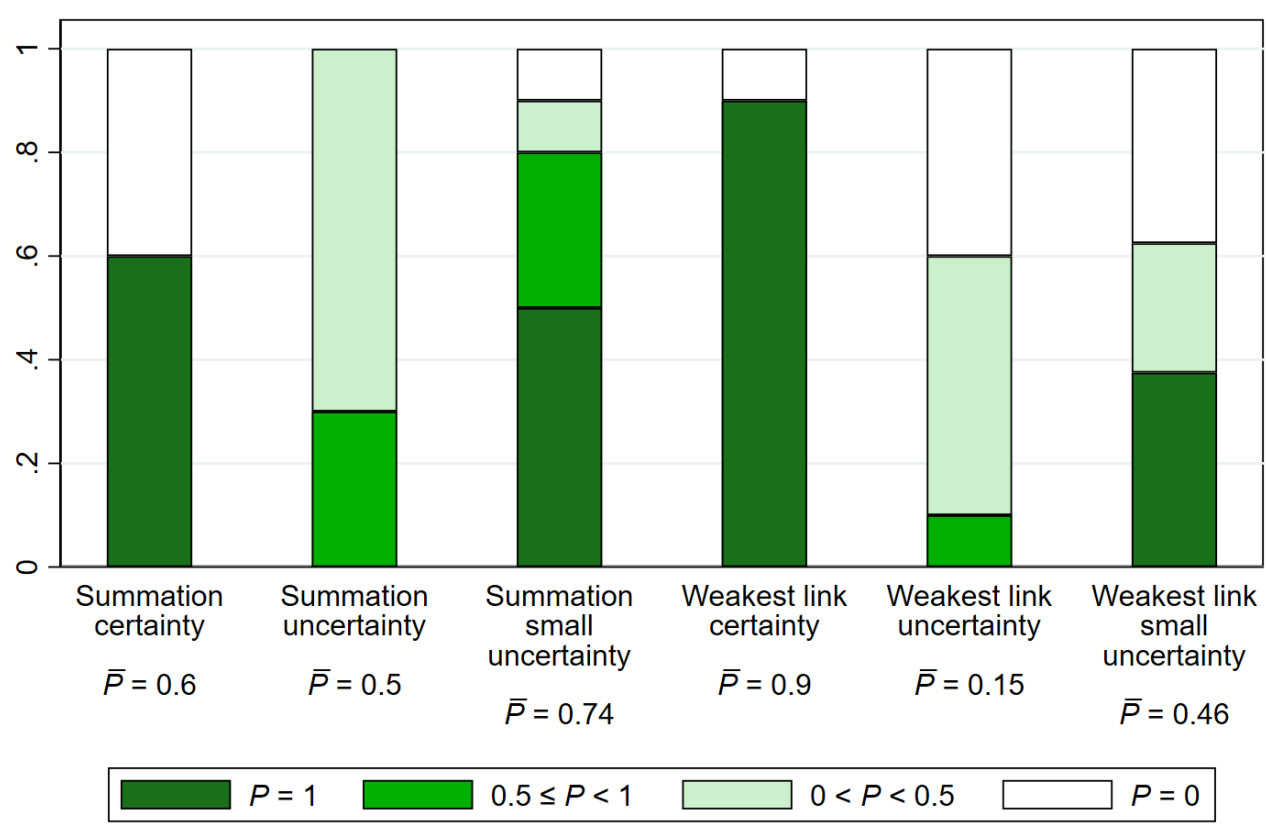


Figure 1. Probability of reaching threshold, by treatment

Starting with the summation treatments, only 60 percent of groups reach the threshold under certainty. Under uncertainty, no group achieves threshold attainment for sure, though this is not surprising given that it would require all 10 group members to contribute all their tokens. What is more noteworthy is that all groups reach the threshold with some positive probability. In fact, the average probability of reaching the threshold under uncertainty is 50 percent. Using a ranksum test against the certainty case and treating each group as an independent observation, we cannot reject the hypothesis of equal distributions $(p=0.442, n=20)$.

This result diverges from the experimental findings of for example Barrett and Dannenberg (2012), where contributions and the probability of reaching the threshold are substantially negatively impacted by threshold uncertainty. There is a similar departure from earlier results for the smaller range of uncertainty (140-160), for which Barrett and Dannenberg (2014) also identified a significant drop in the probability of reaching the threshold relative to the certainty case. In our experiment, the average probability is 0.74 , i.e., even higher than under certainty, although the distributions are not significantly different (ranksum test: $p=0.802, n=20$ ). Thus, we cannot replicate the findings by Barrett and Dannenberg (2014). Interestingly, the difference appears to be driven by different adherence to pledges, as will be explored in Section 4.3. Overall, we conclude that under the summation technology, the rate of threshold attainment is not significantly affected by uncertainty.

We identify a starkly different pattern under the weakest-link technology. Here, $\bar{P}$ is as high as 90 percent under certainty, while it is only 15 percent under uncertainty (ranksum: $p<0.001, n=20$ ). Under uncertainty, 40 percent of the groups are certain to fail to reach the threshold as at least one player contributes less than the lower bound of the threshold distribution. This pattern is present in the small uncertainty treatment too, where there also is a considerable and statistically significant drop in the average probability of reaching the threshold $(46 \%)$ compared with certainty (ranksum; $p=0.033, n=20)$. 
In summary, we conclude that threshold uncertainty negatively impacts the probability of threshold attainment under a weakest-link technology, but not under summation. These results are inconsistent with the predictions made in Table 2, as well as with similar previous studies (Barrett and Dannenberg, 2012, 2014).

\subsection{Individual contributions}

In order to better understand the above patterns of threshold attainment, we now consider individual contributions. Table C2 reports descriptive statistics on contributions across the six treatments. For both summation and weakest link, average contributions are very similar across the certainty and uncertainty treatments. Table $\mathrm{C} 3$ reports results from Tobit models with a left-censoring at 0 and a right-censoring at 20. We include dummy variables for the two treatments with uncertainty, and thus the certainty treatment is the reference case. The two dummy variables for the treatments with uncertainty are statistically insignificant in both the summation and the weakest-link game. Thus, for both aggregation technologies, average contributions do not differ between certainty and uncertainty or small uncertainty.

Yet, it is crucial to gain more detailed insights into the distribution of contributions since a single player who contributes little can be devastating for the chances of reaching the threshold. The full distribution of contributions under the different treatments is given in Figure 2. For summation, the modal contribution is 20 under uncertainty and 15 under certainty; under a small level of uncertainty, the modal contribution is 16 . Thus, the modal contribution consistently coincides with the upper bound of the support of $\bar{Q}$, divided by the number of players. For weakest link, the differences in average contributions are similarly very small. Here, the modal contribution is 15 in both the certainty and the uncertainty treatment, and 16 under small uncertainty.

Also, with summation under certainty, $3 \%$ of subjects contribute zero to the public good and $14 \%$ contribute fewer than 15 tokens. While other players are able to partly compensate for low contributions, successful threshold attainment requires that other group members contribute an average of 16.7 tokens to the 
public good if one player contributes zero; it becomes impossible to reach the threshold if more than two out of 10 people contribute zero. In contrast, the lowest observed contribution in weakest link under certainty is 10 , and 99 percent of subjects contribute 15 tokens or more. Under a weakest-link technology, the threshold thus works very well as a coordinating device.

Uncertainty changes the contribution patterns: under summation, $25 \%$ of subjects contribute the full amount of 20 tokens (vs. 10\% under certainty), yet there are also more subjects contributing fewer than 15 tokens ( $32 \%$ vs. $14 \%$ ). Overall, as already noted, average contributions do not change. For weakest link, $5 \%$ contribute zero under uncertainty (4\% under small uncertainty) and $17 \%$ (8\%) contribute fewer than 15 tokens. Unlike for summation, lowcontributing subjects are truly detrimental for the possibilities of reaching the threshold, since under weakest link the other players cannot compensate for their behavior. The drastic drop in weakest-link threshold attainment under uncertainty is thus largely due to the small minority of zero contributors. 

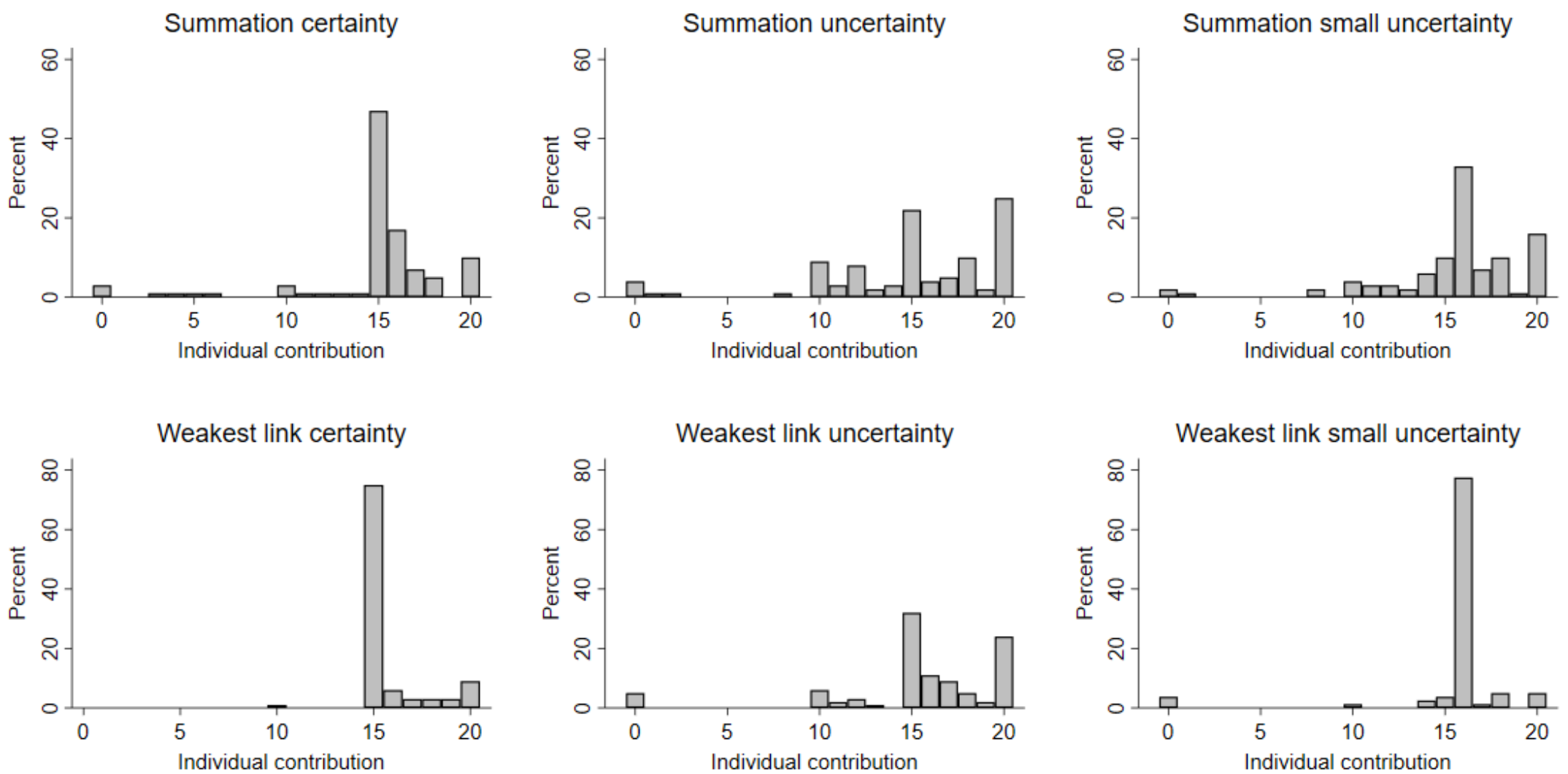

Figure 2. Individual contributions 


\subsection{The role of pledges}

While we have focused on contribution decisions so far, it is crucial to understand whether and how suggested contributions of other group members and individual non-binding contribution pledges affect the contributions in the respective treatments. We begin by investigating whether pledges play a role and then discuss potential mechanisms.

Figure 3 displays the distribution of observed probabilities of reaching the threshold in round 1, i.e., without pledges. ${ }^{9}$ In Table C4 in Appendix C, we report corresponding observed probabilities along with a set of simulated probabilities, each based on 1,000 randomly selected groups with 10 individuals drawn from a given treatment. Unlike Figure 3 (and Figure 1 in Section 4.1), the simulated probabilities do not depend on the group composition actually observed, thus limiting the influence of chance due to the relatively small number of groups that we observe. ${ }^{10}$ However, simulated and observed probabilities are generally quite similar.

\footnotetext{
${ }^{9}$ Note that the group composition in round 1 does not affect any individual behavior in round 2 as no feedback is given between rounds. In order to eliminate the potential impact of randomization of subjects into groups, we thus calculate success probabilities in round 1 based on the group composition in round 2 .

${ }^{10}$ We add simulated probabilities here but not in our analysis of decisions in round 2 because individual contributions are completely independent of other group members only in the first round, where there are no pledges.
} 


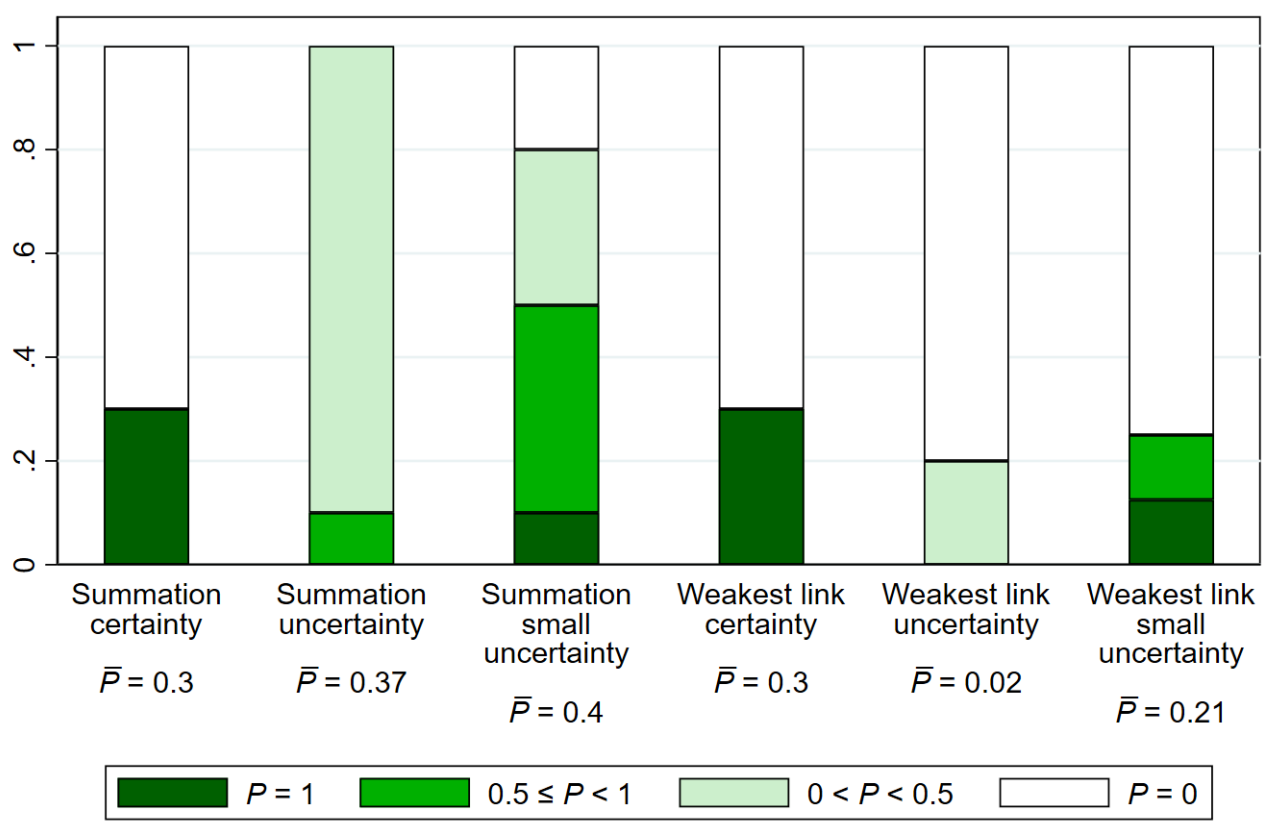

Figure 3. Probability of reaching threshold in treatments without pledges

For all treatments, the probability of reaching the threshold is lower without pledges (round 1) than with pledges (round 2). Threshold attainment for summation under certainty is only 30 percent without pledges, while it is 60 percent with pledges (see Section 4.1). For weakest link under certainty, it is 30 percent rather than the 90 percent obtained following pledges. In fact, in neither of these certainty treatments does any group move from threshold attainment without pledges to non-attainment under pledges. Similarly, we (weakly) reject the hypothesis of equal distributions of probabilities between the rounds with and without pledges using conservative Wilcoxon signed-rank tests for the uncertainty treatments $(74 \%$ vs. $40 \%$ in summation $p=0.049 ; 15 \%$ vs. $2 \%$ in weakest link $\mathrm{p}=0.094)$. Across all treatments, there is no doubt that pledges improve threshold attainment ( $\mathrm{p}<0.001$ for both summation and weakest link). 
The lower probability of reaching the threshold in absence of the possibility to pledge is of course driven by lower contribution levels. ${ }^{11}$ Table C2 in Appendix C gives a full description of contributions. Most importantly, although contributions without pledges are smaller on average and are distributed differently, all comparisons between treatments yield similar results as with pledges. Thus, we again find a lower probability of reaching the threshold for weakest link under uncertainty compared with certainty, while there is no significant drop for the summation game.

For a closer look at contributions with and without pledges, Figure 4 plots each individual's contribution across the two experiments. Many subjects do not change their contribution behavior, and this holds particularly true for subjects making what are arguably focal contributions, such as 15 and 20. Still, there is a shift toward higher levels of contributions with pledges. Under summation and certainty (uncertainty), 49 (31) percent of subjects make the same contribution

\footnotetext{
${ }^{11}$ The standard deviation of contributions is consistently and considerably lower with pledges as well.
} 
in both rounds, while 35 (50) percent increase their contribution with pledges. For weakest link and certainty (uncertainty), 72 (44) percent contribute the same amount in the two rounds, while 22 (46) percent increase their contribution with pledges. Thus, pledges appear especially useful in the uncertainty treatments.

Beyond potentially increasing average contributions, pledges may boost threshold attainment by facilitating better coordination of individual contributions, which is particularly important in weakest-link settings where the

Summation certainty

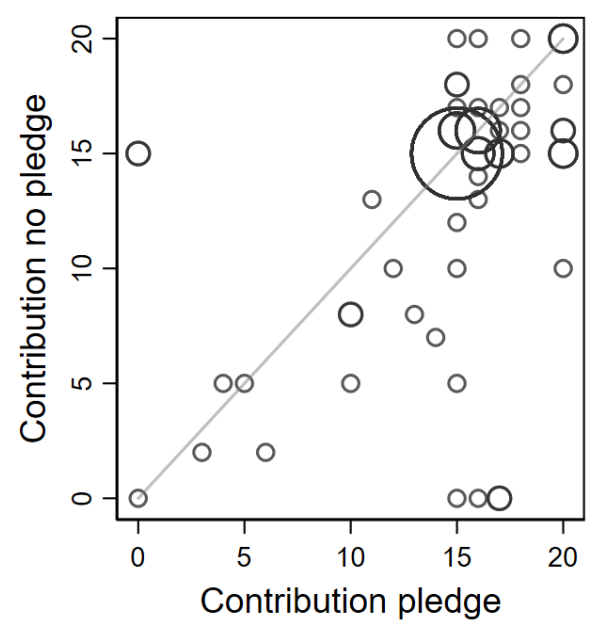

Weakest link certainty

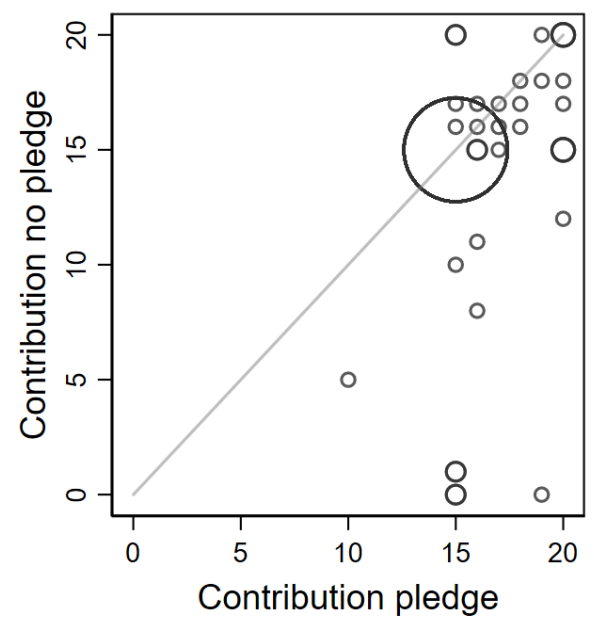

Summation uncertainty

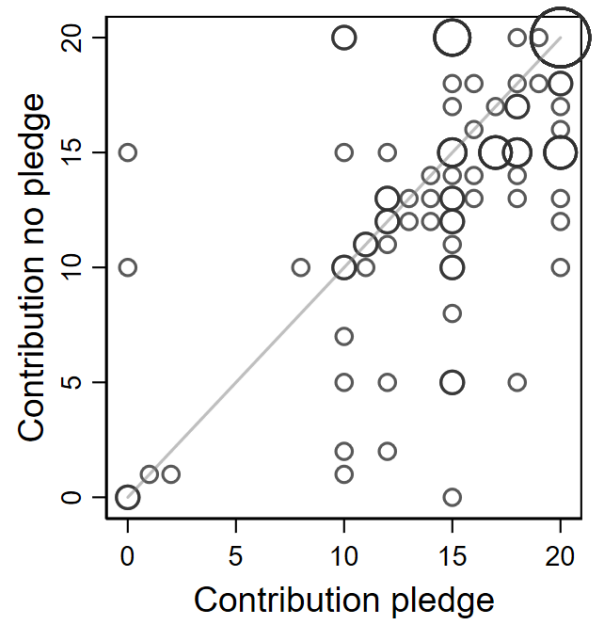

Weakest link uncertainty

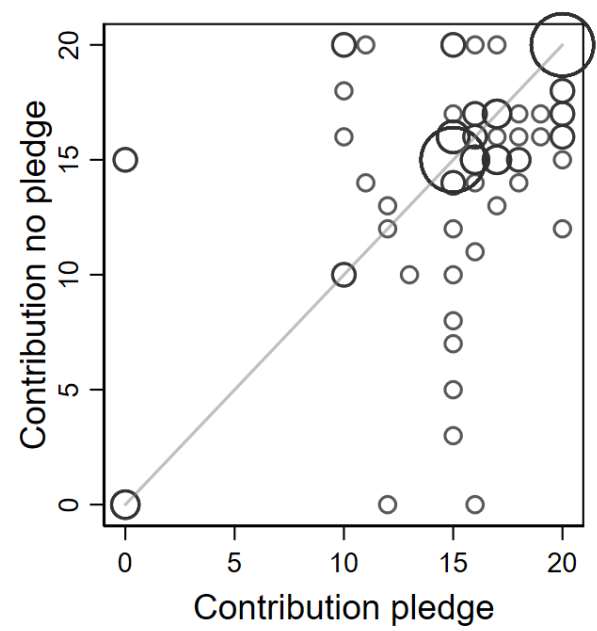

Figure 4. Contributions in experiments with and without pledges 
threshold attainment, and thus welfare, is driven by the smallest contribution level within a group. It is thus crucial to understand the mechanisms through which pledges affect contributions. ${ }^{12}$ For this, we consider two steps: First, how do chosen pledges in round 2 compare against individual contributions in round 1? Second, how do own pledges impact own contribution choices in round 2?

We first examine the connection between round 1 contributions and pledges. Figure 5 plots this relationship. Observations on the 45 degree line pledged the same as they contributed in round 1 , while observations to the right of this line pledged more than round 1. Clearly, pledges are generally higher than contributions in the round without pledges: For summation under certainty (uncertainty), 30\% (51\%) pledged more than they contributed in round 1. For weakest link under certainty (uncertainty), the corresponding figure is $24 \%$ $(37 \%)$. The pattern is confirmed in Wilcoxon signed-rank tests at the individual level (see Table C6 in Appendix C; summation certainty, $p=0.064$; summation uncertainty, $p<0.001$; weakest link certainty, $p<0.001$; weakest link uncertainty, $p=0.015$ ). Thus, subjects make relatively large pledges, possibly to induce higher contributions in round 2.

\footnotetext{
12 Table C2 in Appendix C reports descriptive statistics: contributions in both rounds, pledges, and suggested group contribution (per person). Our analysis focuses on pledges.
} 

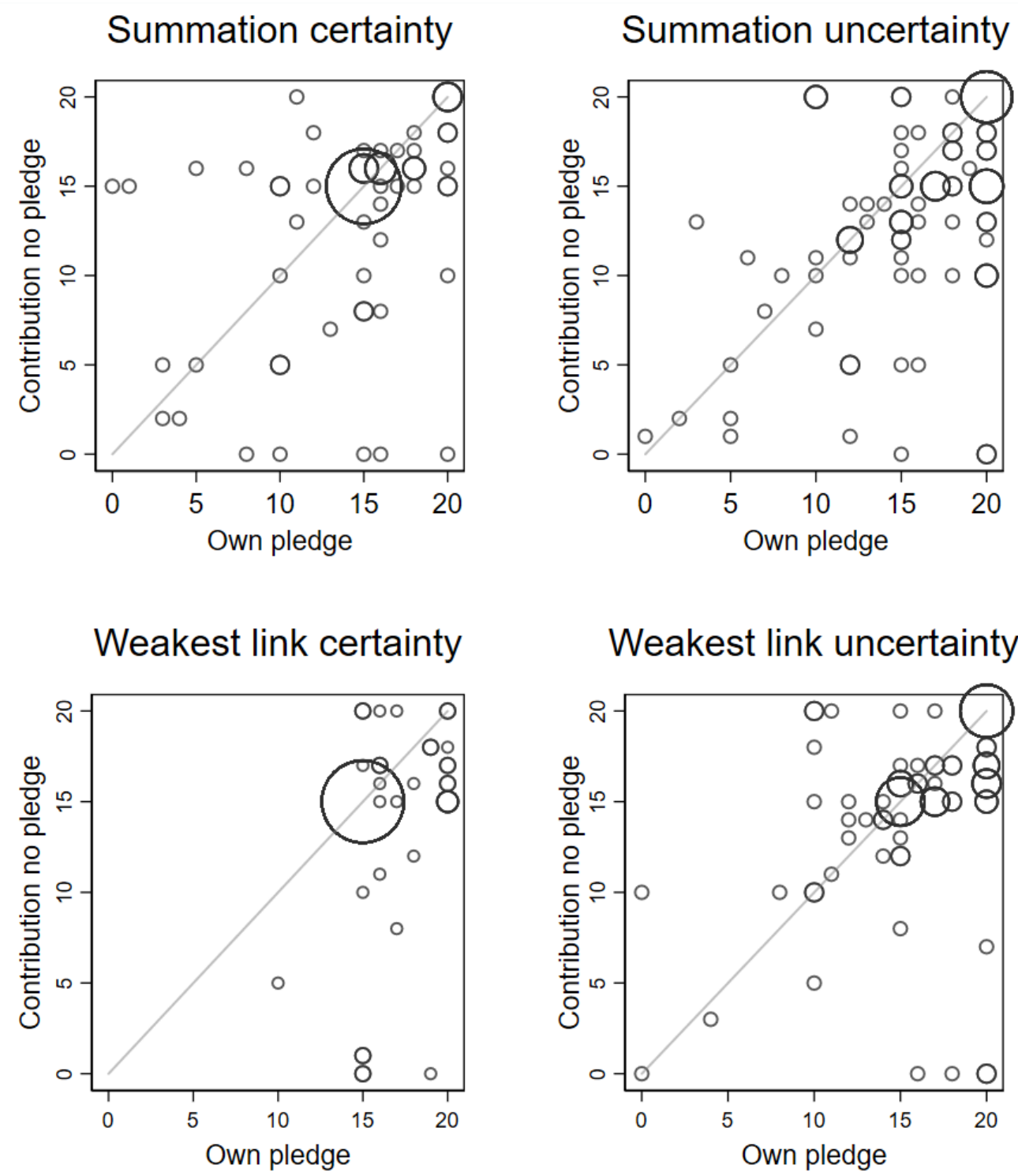

Figure 5. Pledge in round 2 vs. contributions in round 1

Focusing on the weakest-link treatments, two additional observations are particularly noteworthy because they suggest that subjects are indeed using pledges purposefully as a coordination device. First, under certainty, all subjects who contributed fewer than 15 tokens in round 1 pledge higher in round 2. Under uncertainty, there is a similar but slightly weaker pattern that centers on 10 tokens (the lower bound of $\bar{Q}$ ) rather than 15: all subjects who contributed less than 10 in round 1 pledge at least as high in round 2. Second, under 
uncertainty, the modal pledge is 20 . While $23 \%$ contributed this amount in round $1,35 \%$ of subjects pledge to do so in round 2 , thereby attempting to fully eliminate threshold risk. The corresponding numbers for the summation treatment are almost identical (23\% and 36\%, respectively), and a pledge of 20 is modal here as well.

We now move to the second question: to what extent do subjects actually follow through with their pledges? Clearly, subjects seem to have used the pledges as a way to increase or coordinate the contributions by other group members. However, pledges are non-binding. Whether coordination based on pledges is successful or not might differ between summation and weakest-link settings, given that summation allows for (some) free riding, thus potentially providing incentives to renege on the pledge.

To check whether this was the case, Figure 6 scatter plots individual pledges and own contributions in round 2. We see that sizeable fractions of subjects do contribute what they pledged, and they do so in all treatments. For summation under certainty, 52 percent contribute exactly what they pledged, while the corresponding figure for weakest link is 77 percent; under uncertainty, the corresponding numbers are 44 and 51 percent. Indeed, average contributions do not significantly differ from pledges, and this holds under both summation and weakest-link technology, as well as for both the certainty and the uncertainty treatment (Wilcoxon signed-rank test, see Table C5 in Appendix C). Furthermore, the within-group variance of contributions does not differ from the within-group variance of pledges, and the group-minimum pledges do not differ significantly from group-minimum contributions (see Table C5 in 

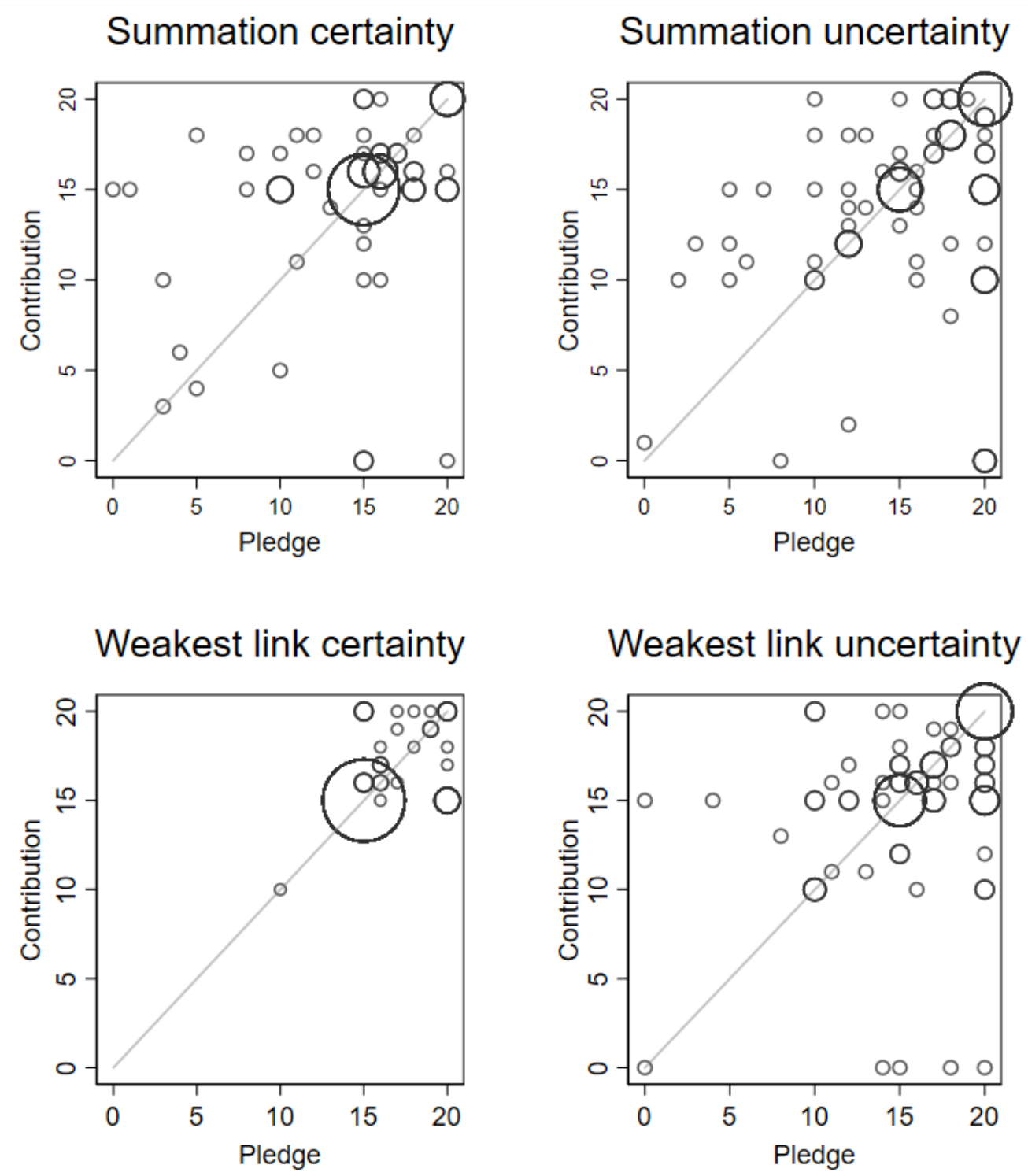

Figure 6. Pledges and own contributions in round 2

Appendix C). We thus conclude that pledges are generally trustworthy. This latter finding is in stark contrast to Barrett and Dannenberg (2014). We have already seen that the contributions under threshold uncertainty are substantially lower in their experiment than in ours. Yet, the pledges in Barrett and Dannenberg (2014) almost coincide with the levels we observe in our experiment, while the final contributions on average are only about $50 \%$ of the pledged amounts. Thus, given our results, threshold uncertainty under 
summation does not necessarily lead to smaller contributions. Rather, its impact depends on the extent to which subjects adhere to their previously made pledges.

\section{Conclusions}

In this paper, we compared the voluntary provision of public goods under different technologies when their provision hinges on thresholds. We explicitly compared two prominent technologies through which individual contributions affect the public good provision: summation and weakest link. While the extant (experimental) literature has so far concentrated on summation, we argued that many important examples of public goods (e.g., terrorism or pandemic diseases) have weakest-link characteristics.

Our experiment investigated the effects of threshold uncertainty on individual contributions and threshold attainment under both technologies. While implementing the exact design of Barrett and Dannenberg $(2012$, 2014) for the summation technology, we were unable to replicate their finding that (large) uncertainty in the level of a threshold is detrimental to its functioning as a coordination device. This difference was particularly driven by pledges being trustworthy in our subject pool.

In contrast, the effects of uncertainty were much more severe in the weakestlink setting. While a certain threshold proved to be a highly successful coordination device, threshold uncertainty reduced the chances of threshold attainment to almost zero. This was despite the fact that each individual subject is more pivotal to the outcome under weakest link, thus potentially making cooperation more likely. What happened instead was that an opposing structural element of weakest link dominated the outcome, namely that low contributions by some subjects cannot be compensated by others. Our experiment thus revealed an important interaction between threshold effects and the technology 
through which individual contributions aggregate into the provision of a public good.

We additionally showed that the success rates for threshold attainment in all treatments heavily hinge on subjects being able to announce non-binding pledges. The benefits of such communication accrue particularly under weakest link. Pledges appeared to create a degree of trust, allowing individuals to make larger (non-binding) pledges than what they would otherwise have contributed. Observing similarly large pledges from other group members, subjects mostly followed through with their pledges.

Our results do underline the difficulty of cooperating to produce a threshold weakest-link public good in the presence of uncertainty. Importantly, we limited our investigation to settings with homogenous players. For summation, heterogeneity regarding endowment or benefits from the public good is known to provide another obstacle to successful cooperation. For weakest link, such heterogeneities might necessitate the implementation of some transfer mechanism even in the absence of uncertainty (e.g., Vicary and Sandler, 2002). While we note the importance of player heterogeneity in real-world threshold weakest-link settings, we leave the investigation of behavior in such situations to future research.

\section{Acknowledgments}

Funding from the Center for Collective Action Research (CeCAR) at the University of Gothenburg is gratefully acknowledged. Andreas Lange acknowledges support by the German Research Foundation (DFG) under Germany's Excellence Strategy, cluster EXC 2037 "Climate, Climatic Change, and Society" (project 390683824). We have received valuable comments from Astrid Dannenberg and seminar participants at the University of Gothenburg. 


\section{References}

Anderson, S. P., Goeree, J. K., \& Holt, C. A. (2001). Minimum-effort coordination games: Stochastic potential and logit equilibrium. Games and Economic Behavior, 34(2), 177-199.

Barbieri, S., \& Malueg, D. A. (2019). On the voluntary provision of "weakestlink" public goods: The case of private information. Journal of Public Economic Theory, 21(5), 866-894.

Barrett, S. (2013). Climate treaties and approaching catastrophes. Journal of Environmental Economics and Management, 66(2), 235-250.

Barrett, S. (2016). Coordination vs. voluntarism and enforcement in sustaining international environmental cooperation. Proceedings of the National Academy of Sciences, 113(51), 14515-14522.

Barrett, S., \& Dannenberg, A. (2012). Climate negotiations under scientific uncertainty. Proceedings of the National Academy of Sciences, 109(43), 17372-17376.

Barrett, S., \& Dannenberg, A. (2014). Sensitivity of collective action to uncertainty about climate tipping points. Nature Climate Change, 4(1), 36-39.

Barrett, S., \& Dannenberg, A. (2016) An experimental investigation into 'pledge and review' in climate negotiations. Climate Change 138(1-2), 339351

Bochet, O., Page, T., \& Putterman, L. (2006). Communication and punishment in voluntary contribution experiments. Journal of Economic Behavior and Organization 60(1), 11-26

Brandts, J., \& Cooper, D. J. (2007). It's what you say, not what you pay: An experimental study of manager-employee relationships in overcoming coordination failure. Journal of the European Economic Association, 5(6), 1223-1268. 
Caparrós, A., \& Finus, M. (2020a). The Corona-Pandemic: A Game-Theoretic Perspective on Regional and Global Governance. Environmental and Resource Economics, 76(4), 913-927.

Caparrós, A., \& Finus, M. (2020b). Public good agreements under the weakest-link technology. Journal of Public Economic Theory, 22(3), 555-582.

Caparrós, A., Blanco, E., Buchenauer, P., \& Finus, M. (2020). Team Formation in Coordination Games with Fixed Neighborhoods. Instituto de Políticas y Bienes Públicos (IPP) CSIC, Working Paper. 2020-04.

Chaudhuri, A., Schotter, A., \& Sopher, B. (2009). Talking ourselves to efficiency: Coordination in inter-generational minimum effort games with private, almost common and common knowledge of advice. The Economic Journal, 119(534), 91-122.

Cornes, R., \& Hartley, R. (2007). Weak links, good shots and other public good games: Building on BBV. Journal of Public Economics, 91(9), 16841707.

Devetag, G., \& Ortmann, A. (2007). When and why? A critical survey on coordination failure in the laboratory. Experimental Economics, 10(3), 331344.

Engelmann, D., \& Normann, H. T. (2010). Maximum effort in the minimumeffort game. Experimental Economics, 13(3), 249-259.

Falk, A., Becker, A., Dohmen, T., Enke, B., Huffman, D., \& Sunde, U. (2018). Global evidence on economic preferences. The Quarterly Journal of Economics, 133(4), 1645-1692.

Fischbacher, U. (2007). z-Tree: Zurich toolbox for ready-made economic experiments. Experimental Economics, 10(2), 171-178. 
Hamman, J., Rick, S., \& Weber, R. A. (2007). Solving coordination failure with "all-or-none" group-level incentives. Experimental Economics, 10(3), 285-303.

Harrison, G. W., \& Hirshleifer, J. (1989). An experimental evaluation of weakest link/best shot models of public goods. Journal of Political Economy, 97(1), 201-225.

Knez, M., \& Camerer, C. (1994). Creating expectational assets in the laboratory: coordination in 'weakest-link'games. Strategic Management Journal, 15(S1), 101-119.

Kotani, K., Tanaka, K., \& Managi, S. (2014). Cooperative choice and its framing effect under threshold uncertainty in a provision point mechanism. Economics of Governance, 15(4), 329-353.

Lei, V., Tucker, S., \& Vesely, F. (2007). Foreign aid and weakest-link international public goods: An experimental study. European Economic Review, 51(3), 599-623.

Riechmann, T., \& Weimann, J. (2008). Competition as a coordination device: Experimental evidence from a minimum effort coordination game. European Journal of Political Economy, 24(2), 437-454.

Riedl, A., Rohde, I. M., \& Strobel, M. (2016). Efficient coordination in weakest-link games. The Review of Economic Studies, 83(2), 737-767.

Steffen, W., Rockström, J., Richardson, K., Lenton, T.M., Folke, C., Liverman, D., Summerhayes, C.P., Barnosky, A.D., Cornell, S.E., Crucifix, M., Donges, J.F., Fetzer, I., Lade, S.J., Scheffer, M., Winkelmann, R., \& Schellnhuber, H.J. (2018). Trajectories of the Earth system in the Antropocene. Proceedings of the National Academy of Sciences, 115(33), 8252-8259. 
Vicary, S., \& Sandler, T. (2002). Weakest-link public goods: Giving in-kind or transferring money. European Economic Review, 46(8), 1501-1520.

Zelmer, J. (2003). Linear public goods experiments: A meta-analysis. Experimental Economics, 6, 299-310. 


\section{Appendix A. Experimental Instructions}

Throughout this appendix, comments and clarifications are made in brackets. In Section B.1.1, note that basic game rules differed across treatment only with respect to the third bullet point on payoffs. In Sections B.1.2 and B.1.3, for brevity we present examples and control questions only for summation under certainty (T1) and weakest link under uncertainty (T5). The corresponding materials used in other treatments are highly similar.

\section{A.1 Introduction and game rules}

Welcome to our experiment!

\section{General information}

In our experiment you can earn money. How much you earn depends on the decisions you and your fellow participants make. For a successful run of this experiment, it is essential that you do not talk to other participants. Now, read the following rules of the game carefully. If you have any questions, please raise your hand. Once everyone has read the instructions, we will give a brief oral presentation before continuing.

The experiment will consist of two parts. One of the two parts will be randomly picked and your final payouts will be based on the decisions you and other participants make in this part. It is therefore important that you pay close attention to the instructions. After the two parts, we have some background and attitude questions to ask you as well.

You will receive an initial endowment of $€ 15$ for your participation. Any loss during the experiment will be deducted from that amount, and gains will be added.

\section{Rules for part 1}

You are in a group of ten participants, meaning you and nine other persons. Each group member faces the same decision problem. All decisions in the experiment are anonymous. For the purpose of anonymity, you will be identified by a letter (between A and J), which you will see in the lower left corner of the screen.

At the beginning of the game, you will receive 20 tokens, which are credited to two personal accounts, Account A and Account B. You will have 10 tokens in each account. In the experiment, you can use the tokens to contribute to a joint project or you can leave them in the two accounts. 
Tokens from Account A are worth $€ 0.10$ each. Tokens from Account B are worth $€ 0.50$ each. You can contribute any integer amount of tokens between 0 and 20 to the joint project - at most 10 tokens from Account A and at most 10 tokens from Account B.

The payment at the end of the game will consist of the following parts:

- The amount of tokens you have left in Accounts A and B will be paid to you in cash: $€ 0.10$ for each token left in Account $A$ and $€ 0.50$ for each token left in Account B.

- You and all other participants in the group will get $€ 0.05$ for every token contributed to the joint project, irrespective of who contributed the token and whether it was a token from Account A or B.

- [Summation, certainty:] If the group as a whole contributes fewer than 150 tokens to the joint project, every member of the group will lose $€ 15$. If the group contributes 150 or more tokens to the joint project, no participant will lose any money.

- [Summation, uncertainty:] If the group as a whole contributes less than a certain minimum amount of tokens to the joint project, every player will lose $€ 15$. If the group contributes the minimum amount or more to the joint project, no player will lose any money. The minimum amount of tokens is not known beforehand. What you know is that it is between 100 and 200 [T3: between 140 and 160], that each integer value from 100 to 200 has the same probability of being selected, and that the minimum amount will be randomly drawn after the decisions have been made.

- [Weakest link, certainty:] If any group member contributes fewer than 15 tokens to the joint project, every player will lose $€ 15$. If each member of the group contributes 15 or more tokens to the joint project, no player will lose any money.

- [Weakest link, uncertainty:] If any group member contributes less than a certain minimum amount of tokens to the joint project, every player will lose $€ 15$. If each member of the group contributes the minimum amount or more to the joint project, no player will lose any money. The minimum amount of tokens is not known beforehand. What you know is that it is between 10 and 20 [T6: 14 and 16], that each integer value from 10 to 20 has the same probability of being selected, and that the minimum amount will be randomly drawn after the decisions have been made.

Note that you can contribute any number of tokens between 0 and 20 . These contributions will automatically first be deducted from your Account A (up to ten tokens), before tokens are taken out of Account B (up to another ten tokens).

This game will be played only once. You should think carefully about how to decide in the game. Before playing, we will go through two examples. The examples are presented on the next two pages, but will also be shown on the screen. Therefore, please click on the screen to move to the examples on the 
screen. Please note that these examples are for illustration only, so you will not be able to choose contribution levels.

[Examples and control questions, followed by play in part 1. Immediately before part 2, the following instructions were given.]

\section{A change in the rules}

We will now ask you to make decisions in a similar setting as before. However, there is a change in how the game proceeds and again it is important for you to pay close attention to the instructions.

In addition, we will reshuffle the groups so you will play with a different group of people than in Part 1 of the experiment.

[Summation treatments:] The difference is that before you and the other participants decide how many tokens to contribute, everyone will be given an opportunity to make two non-binding announcements. First, each participant will make a proposal (between zero and 200) about how many tokens the group as a whole should contribute to the joint project. Second, each participant will make a pledge (between zero and 20) for how many tokens he or she intends to contribute to the joint project. All proposals and pledges made by the players will be displayed before you and the other participants decide how much to contribute.

[Weakest link treatments:] The difference is that before you and the other participants decide how many tokens to contribute, everyone will be given an opportunity to make two non-binding announcements. First, each participant will make a proposal (between zero and 20) about how many tokens each group member should contribute to the joint project. Second, each participant will make a pledge (between zero and 20) for how many tokens he or she intends to contribute to the joint project. All proposals and pledges made by the players will be displayed before you and the other participants decide how much to contribute.

In all other respects, the game is the same as before, but we will still repeat these other rules here. $[\ldots]$ 


\section{A.2 Examples}

\section{Example 1 [Summation, certainty]}

Here, you can see a hypothetical example of the decisions made by ten participants.

\begin{tabular}{crr}
\hline Participant & Contribution & Payoff in Part 1 \\
\hline A & 0 & -4.4 \\
B & 0 & -4.4 \\
C & 10 & -5.4 \\
D & 0 & -4.4 \\
E & 12 & -6.4 \\
F & 10 & -5.4 \\
G & 8 & -5.2 \\
H & 15 & -7.9 \\
I & 17 & -8.9 \\
J & 20 & -10.4 \\
\hline Total & 92 & \\
\hline
\end{tabular}

The contribution column displays each participant's actual contribution to the joint project. The final column shows the total payoff for each group member. The payoff depends on the number of tokens left in Accounts A and B, payoff from total contributions to the joint project, and whether there is a loss.

The total contribution of 92 tokens to the joint project means that each member receives $€ 0.05$ times $92=€ 4.60$ from the joint project. In addition, since total contributions are less than 150 , every player will incur a loss of $€ 15$.

Let us look at two participants to see how total payoff is determined.

Participant A did not contribute anything so he/she will receive 10 times $€ 0.10$ from Account $\mathrm{A}$ and 10 times $€ 0.50$ from Account $\mathrm{B}$, totaling $€ 6$. If we add everything together, we have that player A will get $6+4.6-15=-€ 4.4$. This loss will be deducted from the endowment of $€ 15$.

Participant $\mathrm{H}$ contributed 15 tokens (10 from Account $\mathrm{A}$ and 5 from Account $\mathrm{B})$, so he/she will receive 5 times $€ 0.50$ from Account $\mathrm{B}$, which is equal to $€ 2.50$. If we add everything together, we get that player $C$ will get $2.5+4.6-$ $15=-€ 7.9$.

\section{Example 2 [Summation, certainty]}

Here is another hypothetical example of the decisions made by the ten group members. 


\begin{tabular}{crr}
\hline Participant & Contribution & Payoff in Part 1 \\
\hline A & 15 & 10.3 \\
B & 15 & 10.3 \\
C & 15 & 10.3 \\
D & 15 & 10.3 \\
E & 15 & 10.3 \\
F & 15 & 10.3 \\
G & 16 & 9.8 \\
H & 20 & 7.8 \\
I & 15 & 10.3 \\
J & 15 & 10.3 \\
\hline Total & 156 & \\
\hline
\end{tabular}

The total contribution of 156 tokens to the joint project means that each participant receives $€ 0.05$ times $156=€ 7.80$ from the joint project. In addition, since total contributions are higher than 150 , there will be no loss of $€ 15$.

Let us look at two participants to see how total payoff is determined.

Participant A contributed 15 tokens (10 from Account A and 5 from Account $\mathrm{B})$, so he/she will receive 5 times $€ 0.50$ from Account $\mathrm{B}$, which equals $€ 2.50$. If we add everything together, participant $\mathrm{A}$ will get $2.5+7.8=€ 10.3$. This gain will be added to the endowment of $€ 15$.

Participant $\mathrm{H}$ contributed 20 tokens (10 from Account A and 10 from Account B). This means that the player will only get a payment from the joint project: $€ 7.80$.

Example 1 [Weakest link, uncertainty]

Here, you can see a hypothetical example of the decisions made by ten participants.

\begin{tabular}{lll}
\hline Participant & Contribution & Payoff in Part 1 \\
\hline A & 0 & -4.4 \\
B & 0 & -4.4 \\
C & 10 & -5.4 \\
D & 0 & -4.4 \\
E & 12 & -6.4 \\
F & 10 & -5.4 \\
G & 8 & -5.2 \\
H & 15 & -7.9 \\
I & 17 & -8.9 \\
J & 20 & -10.4 \\
\hline Total & 92 & \\
\hline
\end{tabular}


The contribution column displays each participant's actual contribution to the joint project. The final column shows the total payoff for each group member. The payoff depends on the number of tokens left in Accounts A and B, payoff from total contributions to the joint project, and whether there is a loss or not.

The total contribution of 92 tokens to the joint project means that each member receives $€ 0.05$ times $92=€ 4.60$ from the joint project. The required minimum amount of tokens for no loss is between 10 and 20, and since at least one member contributed less than 10 tokens, every player will incur a loss of $€ 15$.

Let us look at two participants to see how total payoff is determined.

Participant A did not contribute anything so he/she will receive 10 times $€ 0.10$ from Account $\mathrm{A}$ and 10 times $€ 0.50$ from Account $\mathrm{B}$, totaling $€ 6$. If we add everything together, player A will get $6+4.6-15=-€ 4.4$. This loss will be deducted from the endowment of $€ 15$.

Participant $\mathrm{H}$ contributed 15 tokens (10 from Account A and 5 from Account $B$ ), so he/she will receive 5 times $€ 0.50$ from Account $B$, which equals $€ 2.50$. If we add everything together, player $\mathrm{C}$ will get $2.5+4.6-15=-€ 7.9$.

Example 2 [Weakest link, uncertainty]

Here is another hypothetical example of the decisions made by the ten group members.

\begin{tabular}{llll}
\hline Participant & Contribution & $\begin{array}{l}\text { Payoff with no } \\
\text { loss in Part 1 }\end{array}$ & $\begin{array}{l}\text { Payoff with } \\
\text { loss in Part 1 }\end{array}$ \\
\hline A & 15 & 10.3 & -4.7 \\
B & 15 & 10.3 & -4.7 \\
C & 15 & 10.3 & -4.7 \\
D & 15 & 10.3 & -4.7 \\
E & 15 & 10.3 & -4.7 \\
F & 15 & 10.3 & -4.7 \\
G & 16 & 9.8 & -5.2 \\
H & 20 & 7.8 & -7.2 \\
I & 15 & 10.3 & -4.7 \\
J & 15 & 10.3 & -4.7 \\
\hline Total & 156 & & \\
\hline
\end{tabular}

The total contribution of 156 tokens to the joint project means that each participant receives $€ 0.05$ times $156=€ 7.80$ from the joint project. Since all players contributed between 10 and 20, we do not know for sure whether there will be a loss of $€ 15$. The lowest contribution is 15 (players A, C, E, F). If the random draw of the required minimum amount of tokens is 15 or lower, then 
there is no loss. If the random draw of the required minimum amount of tokens is larger than 15 , then there is a loss. We therefore have two columns with payoffs in the table.

Let us look at two participants to see how total payoff is determined.

Participant A contributed 15 tokens (10 from Account A and 5 from Account $B)$, so he/she will receive 5 times $€ 0.50$ from Account $B$, which equals $€ 2.50$. If we add everything together, participant $\mathrm{A}$ will get $2.5+7.8=€ 10.3$ if there is no loss. If there is a loss, the payoff will be $2.5+7.8-15=-€ 4.7$.

Participant $\mathrm{H}$ contributed 20 tokens (10 from Account A and 10 from Account $B)$. This means that if there is no loss the player will only get a payment from the joint project: $€ 7.80$. If there is a loss, the payoff will be $7.8-15=-€ 7.2$. 


\section{A.3 Control questions}

(a) Take a look at the hypothetical example below (same as the first example we looked at before). Are the contributions [Summation treatments: "collective contributions"] within the group sufficient to avoid the loss?

$\circ$ Yes $\circ$ No

[Summation, uncertainty treatments: $\odot$ It depends on the random draw]

\begin{tabular}{ll}
\hline Participant & Contribution \\
\hline A & 0 \\
B & 0 \\
C & 10 \\
D & 0 \\
E & 12 \\
F & 10 \\
G & 8 \\
H & 15 \\
I & 17 \\
J & 20 \\
\hline Total & 92 \\
\hline
\end{tabular}

(b) Assume that the group as a whole (including you) has contributed 0 tokens to the joint account so that there is a loss of $€ 15$. What would be your total payoff from the game (excluding the initial endowment of $€ 15$ )?

$$
\begin{array}{lllll}
\circ-15 & \circ-9 & \circ 0 & \circ 6 & \circ 15
\end{array}
$$

(c) Assume that the group as a whole (including you) has contributed 150 tokens to the joint project. How much would each participant receive in payment from the joint project only?
$\circ 0$
$\circ 5$
$\circ 7.5$
$\circ 10$
$\circ 15$

[Summation, certainty] (d) What is the lowest number of tokens the group must reach to avoid the loss?
$\circ 0$
$\circ 50$
$\circ 100$
$\circ 150$
○ 200

[Summation, uncertainty (T2, T3)] (d) What is the lowest number of tokens the group must reach to have some possibility to avoid the loss?
$\circ 100$
$\circ 140$
$\circ 150$
○ 160
○ 200 
[Summation, uncertainty $(T 2, T 3)]$ (e) How many tokens must the group reach to be sure to avoid the loss?
$\circ 100$
$\circ 140$
$\circ 150$
$\circ 160$
○ 200

[Weakest link, certainty] (d) What is the lowest number of tokens each participant must contribute to the joint account in order to avoid the loss?
$\circ 0$
$\circ 5$
$\circ 10$
$\circ 15$
$\circ 20$

[Weakest link, uncertainty (T5, T6)] (d) What is the lowest number of tokens each participant must contribute to the joint account to have some possibility to avoid the loss?
$\circ 10$
$\circ 14$
$\circ 15$
$\circ 16$
$\circ 20$

[Weakest link, uncertainty (T5, T6)] (e) How many tokens must each participant contribute to the joint account to be sure to avoid the loss?
$\circ 10$
$\circ 14$
$\circ 15$
○ 16
○ 20 


\section{A.4 Survey questions}

1. Did you trust the other players to make the contributions they pledged?

$\square$ Very much

$\square$ Somewhat

$\square$ Not much

$\square$ Not at all

2. Can you can describe the main reasons you did or did not trust the pledges made by the other participants.

3. What was the most important reason for your pledge?

$\square$ To signal my intended contribution

$\square$ To get others to contribute

$\square$ Other reason:

4. Did other group members' pledges affect your own contribution?

$\square$ No

$\square$ Yes, it made me increase my contribution relative to what I initially intended to contribute.

$\square$ Yes, it made me decrease my contribution relative to what I initially intended to contribute.

5. Did other group members' proposals for the group contribution affect your own contribution?

$\square$ No

$\square$ Yes, it made me increase my contribution relative to what I initially intended to contribute.

$\square$ Yes, it made me decrease my contribution relative to what I initially intended to contribute.

6. Please tell me, in general, how willing or unwilling you are to take risks. Please use a scale from 0 to 10 , where 0 means you are" completely unwilling to take risks" and a 10 means you are "very willing to take risks."

7. We now ask for your willingness to act in a certain way in four different areas. Please again indicate your answer on a scale from 0 to 10 , where 0 means you are "completely unwilling to do so" and a 10 means you are "very willing to do so".

a. How willing are you to give up something that is beneficial for you today, in order to benefit more from it in the future?

b. How willing are you to punish someone who treats you unfairly, even if there may be costs for you? 
c. How willing are you to punish someone who treats others unfairly, even if there may be costs for you?

d. How willing are you to give to good causes without expecting anything in return?

8. How well do the following statements describe you as a person? Please indicate your answer on a scale from 0 to 10. A 0 means "does not describe me at all" and a 10 means "describes me perfectly."

a. When someone does me a favor, I'm willing to return it

b. If I am treated very unjustly, I will take revenge at the first occasion, even if there is a cost to do so.

c. I assume that people have only the best intentions.

9. Please imagine the following situation: You can choose between a sure payment of a particular amount of money, or a draw, where you would have an equal chance of getting 300 euro and getting nothing. We will present to you five different situations. [Followed by five lottery choices, where later lotteries condition on earlier choices]

10. Please think about what you would do in the following situation. You are in an area you are unfamiliar with and realize that you are lost. You ask a stranger for directions. The stranger offers to take you to your destination. Helping you costs the stranger about 20 euro in total. However, the stranger says he or she does not want any money from you. You have six presents with you. The cheapest present costs 5 euro, the most expensive one costs 30 euro. Do you give one of the presents to the stranger as a "thank you" gift? If so, which present do you give to the stranger?

$\square$ no present

$\square$ the present worth 5 euro

$\square$ the present worth 10 euro

$\square$ the present worth 15 euro

$\square$ the present worth 20 euro

$\square$ the present worth 25 euro

$\square$ the present worth 30 euro

11. Imagine the following situation: Today you unexpectedly received 1,000 euro. How much of this amount would you donate to a good cause? (Values between 0 and 1,000 are allowed)

euro

12. What is your gender?

$\square$ Male 
$\square$ Female

13. What is your year of birth?

14. In what academic domain does your major belong?
$\square$ Natural sciences
$\square$ Social sciences
$\square$ Humanities
$\square$ Business
$\square$ Economics
$\square$ Law 


\section{Appendix B. Theoretical guidance}

Here we derive best responses and characterize associated Nash equilibria for each treatment in the experiment. We limit the attention to symmetric equilibria. Since endowments have no impact on best responses, we disregard them throughout the analysis. We also do not consider proposals and pledges of the kind offered in the second round of the game. Players are assumed to be risk neutral throughout.

Recall that each player $i \in\{1, \ldots, 10\}$ chooses how many tokens $q_{i} \in$ $\{0,1, \ldots, 20\}$ to contribute. For fixed player $i$, define $q_{-i}=\sum_{j \neq i} q_{j}$ as the sum of

other group members' contributions and $q_{i}^{\min }=\min _{i}\left(q_{i}\right)$ as the smallest contribution by any player. The threshold $\bar{Q}$ is uniformly distributed on integers $\{a, a+1, \ldots, b-1, b\}$, with $b \geq a>0$.

Each player's opportunity cost of contributing is piecewise linear and convex,

$$
C\left(q_{i}\right)=\left\{\begin{aligned}
0.1 q_{i}, & \text { for } 0 \leq q_{i} \leq 10 \\
1+0.5\left(q_{i}-10\right), & \text { for } 11 \leq q_{i} \leq 20
\end{aligned}\right.
$$

while total returns from contributing (after resolving the uncertainty in $\bar{Q}$ ) are

$$
0.05\left(q_{i}+q_{-i}\right)-15 f\left(q_{1}, \ldots, q_{n}, \bar{Q}\right)
$$

where $f$ is a discontinuous function of the contributions and the threshold level. Under a summation technology, $f=I\left(q_{i}+q_{-i}<\bar{Q}\right)$, where $I$ is the binary indicator function. Under a weakest-link technology, $f=I\left(q_{i}^{\min }<\bar{Q}\right)$.

\section{B.1 Summation technology}

\section{B.1.1 Certain threshold (T1)}

When the threshold level is certain, $\bar{Q}=150$, payoffs to agent $i$ are

$U\left(q_{i}, q_{-i}\right)=0.05\left(q_{i}+q_{-i}\right)-C\left(q_{i}\right)-15 I\left(q_{i}+q_{-i}<150\right)$. 
We will now analyze $i$ 's best response $q_{i}\left(q_{-i}\right)$, being a function of $q_{-i}$, the summed contributions of other players. There are three cases, and we will check whether best responses in each case support some symmetric equilibrium where $q_{i}\left(q_{-i}\right)=q_{-i} / 9$.

First, if $q_{-i}<130$, the last term in the utility function equals 15 regardless of $q_{i}$, so utility is everywhere decreasing in own contributions since marginal costs of contributing are always at least 0.1 . Thus, $q_{i}\left(q_{-i}\right)=0$ is optimal in this range, supporting a non-cooperative Nash equilibrium where $q_{i}=0$ for all $i$.

Second, if $130 \leq q_{-i}<150$, player $i$ is pivotal in reaching the threshold. Clearly, contributing either zero or $150-q_{-i}$ will be optimal; the latter is the case when

$$
0.05 \times 150-C\left(150-q_{-i}\right)>0.05 q_{-i}-15
$$

which is always true given our parameter values. Thus, $q_{i}\left(q_{-i}\right)=150-q_{-i}$ in this range. This supports a symmetric coordination/cooperation equilibrium at $q_{i}=15$ for all $i$, where all players have $q_{-i}=135$.

Finally, if $q_{-i} \geq 150$, the threshold is certain to be reached regardless of $q_{i}$, and it follows that $q_{i}\left(q_{-i}\right)=0$, similarly to the first case. Thus, no symmetric equilibrium is supported.

In summary, there are two symmetric Nash equilibria: a noncooperative one at $q_{i}=0$ for all $i$ and a coordination/cooperation equilibrium at $q_{i}=15$.

\section{B.1.2 Uncertain threshold (T2, T3)}

When the location of threshold $\bar{Q}$ is uncertain, expected payoffs for risk-neutral players are given by

$$
E\left[U\left(q_{i}, q_{-i}\right)\right]=0.05\left(q_{i}+q_{-i}\right)-C\left(q_{i}\right)-15 P\left(q_{i}+q_{-i}<\bar{Q}\right)
$$


where $P(\cdot)$ is the probability of failing to reach the uniformly distributed threshold. Again, the best response of player $i$ is a function of $q_{-i}$, and symmetric equilibria have $q_{i}\left(q_{-i}\right)=q_{-i} / 9$. The main difference is that there are now five cases, which we will discuss in turn. Note that $b-a=100$ under large uncertainty (T2) and $b-a=20$ under small uncertainty (T3).

First, if $q_{-i}<a-20$, then $P=1$ regardless of $q_{i}$, so then $q_{i}\left(q_{-i}\right)=0$, again because marginal payoffs from contributing are everywhere negative. These best responses clearly support a Nash equilibrium where $q_{i}=0$ for all $i$.

Second, if $a-20 \leq q_{-i}<a-1$, then player $i$ is able to marginally impact the probability of threshold attainment, but only after having contributed the first $(a-1)-q_{-i}$ units. This implies that expected payoffs become

$$
E\left[U\left(q_{i}, q_{-i}\right)\right]=0.05\left(q_{i}+q_{-i}\right)-C\left(q_{i}\right)-15 \times \min \left(1, \frac{b-\left(q_{i}+q_{-i}\right)}{b-a+1}\right)
$$

where the final term reflects the discrete uniform distribution of $\bar{Q}$; recall that $\bar{Q}$ may take $b-a+1$ values. Thus, the marginal utility of the initial unit(s) contributed by $i$ is negative, but if $q_{i}$ enters the range where $P<1$ while $q_{i} \leq$ 10 , then the marginal utility becomes $-0.05+15 /(b-a+1)$, which is positive under both large and small uncertainty. Furthermore, $i$ 's marginal utility of contributing more than 10 units while impacting $P$ is $-0.45+$ $15 /(1+b-a)$, which is negative under large uncertainty but positive under small uncertainty. It follows that, under large uncertainty, either $q_{i}\left(q_{-i}\right)=0$ or $q_{i}\left(q_{-i}\right)=10$. Under small uncertainty, either $q_{i}\left(q_{-i}\right)=0$ or $q_{i}\left(q_{-i}\right)=20$.

For our particular parameter values, we find the following. Under large uncertainty, where $a=100, q_{i}\left(q_{-i}\right)=10$ for $93 \leq q_{-i} \leq 98$, and is zero otherwise. Under small uncertainty, where $a=140, q_{i}\left(q_{-i}\right)=20$ for $126 \leq$ $q_{-i} \leq 138$, and is zero otherwise. No Nash equilibria are supported by these best responses. 
Third, when $a-1 \leq q_{-i} \leq b-20$, the choice of player $i$ always affects $P$, so expected payoffs are

$$
E\left[U\left(q_{i}, q_{-i}\right)\right]=0.05\left(q_{i}+q_{-i}\right)-C\left(q_{i}\right)-15 \times \frac{b-\left(q_{i}+q_{-i}\right)}{b-a+1}
$$

which, by similar reasoning as above, implies $q_{i}\left(q_{-i}\right)=10$ under large uncertainty, and $q_{i}\left(q_{-i}\right)=20$ under small uncertainty. Again, no Nash equilibria are supported in this range.

Fourth, when $b-20<q_{-i}<b$, player $i$ starts out being pivotal; but the threshold is met with certainty for high enough $q_{i}$, and $P=0$ for any contribution beyond that point. It follows that payoffs are

$$
E\left[U\left(q_{i}, q_{-i}\right)\right]=0.05\left(q_{i}+q_{-i}\right)-C\left(q_{i}\right)-15 \times \max \left(0, \frac{b-\left(q_{i}+q_{-i}\right)}{b-a+1}\right)
$$

implying that under large uncertainty, $q_{i}\left(q_{-i}\right)=\min \left(10, b-q_{-i}\right)$, while under small uncertainty, $q_{i}\left(q_{-i}\right)=b-q_{-i}$. For large uncertainty, no Nash equilibrium is supported by these patterns; but for small uncertainty, a coordination/cooperation equilibrium is supported at $q_{i}=16$ for all $i$, where all players have $q_{-i}=b-16=144$.

Finally, if $q_{-i} \geq b, P=1$ regardless of $q_{i}$, so then $q_{i}\left(q_{-i}\right)=0$. Thus, no Nash equilibrium is supported in this range.

In summary, for large uncertainty, the only symmetric equilibrium is the noncooperative one where $q_{i}=0$ for all $i$. For small uncertainty, there is additionally an equilibrium at $q_{i}=16$ for all $i$.

\section{B.2 Weakest-link technology}

B.2.1 Certain threshold (T4) 
When the weakest-link threshold is certain and equal to $\bar{Q}=15$, payoffs to player $i$ are

$U\left(q_{i}, q_{-i}, q_{i}^{\min }\right)=0.05\left(q_{i}+q_{-i}\right)-C\left(q_{i}\right)-15 I\left(q_{i}^{\min }<15\right)$.

.In this game, the best response of player $i$ may be analyzed as a function of $q_{-i}^{\min }=\min _{j \neq i}\left(q_{j}\right)$, the lowest contribution of any player other than $i$. There are only two cases, each of which will support a symmetric Nash equilibrium whenever $q_{i}\left(q_{-i}^{\min }\right)=q_{-i}^{\min }$.

First, if $q_{-i}^{\min }<15$, then regardless of $q_{i}$, the threshold will not be met; therefore, since the marginal utility of contributing is negative, $q_{i}\left(q_{-i}^{\min }\right)=0$, supporting a noncooperative equilibrium where $q_{i}=0$ for all $i$.

Second, if $q_{-i}^{\min } \geq 15$, then payoffs for player $i$ are given by

$$
U\left(q_{i}, q_{-i}, q_{i}^{\min }\right)=0.05\left(q_{i}+q_{-i}\right)-C\left(q_{i}\right)-15 I\left(q_{i}<15\right)
$$

and $i$ 's best response is either zero or 15 . In fact, since $0.05 \times 15-1-$ $0.5 \times 5=-2.75>-15$, it is $q_{i}\left(q_{-i}^{\min }\right)=15$. This supports an equilibrium where $q_{i}=15$ for all $i$.

In summary, there are two symmetric Nash equilibria: a non-cooperative one at $q_{i}=0$ for all $i$, and a coordination/cooperation equilibrium at $q_{i}=15$.

\section{B.2.2 Uncertain threshold (T5, T6)}

When the location of the threshold is uncertain, expected payoffs for risk neutral agents are

$$
E\left[U\left(q_{i}, q_{-i}, q_{-i}^{\min }\right)\right]=0.05\left(q_{i}+q_{-i}\right)-C\left(q_{i}\right)-P\left(q_{i}^{\min }<\bar{Q}\right)
$$


Again, the best response of player $i$ is a function of $q_{-i}^{\min }$, and symmetric equilibria have $q_{i}\left(q_{-i}^{\min }\right)=q_{-i}^{\min }$. There are again two cases. Note that $b-a=$ 10 under large uncertainty (T5) and $b-a=2$ under small uncertainty (T6).

First, if $q_{-i}^{\min }<a$, then $P=1$, so $q_{i}\left(q_{-i}^{\min }\right)=0$ in this case, supporting a noncooperative equilibrium where $q_{i}=0$ for all $i$.

Second, if $q_{-i}^{\min } \geq a$, player $i$ is pivotal for threshold attainment up to the point where $q_{i}=q_{-i}^{\min }$ or, if $q_{-i}^{\min } \geq b$, the point where $q_{i}=b$ and thus $P=0$. As a result, payoffs to player $i$ are

$$
\begin{aligned}
& E\left[U\left(q_{i}, q_{-i}, q_{-i}^{\min }\right)\right] \\
& \quad=0.05\left(q_{i}+q_{-i}\right)-C\left(q_{i}\right) \\
& \quad-15 \times \min \left(1, \max \left(\frac{b-q_{i}}{b-a+1}, \max \left(0, \frac{b-q_{-i}^{\min }}{b-a+1}\right)\right)\right) .
\end{aligned}
$$

Because of the weakest-link structure of the game, it will never be optimal for player $i$ to contribute more than $\min \left(q_{-i}^{\min }, b\right)$ tokens. Furthermore, the first nine units contributed by player $i$ can never affect the probability of threshold attainment. Under large uncertainty, the tenth unit contributed will marginally impact $P$ : this unit yields marginal payoff $-0.05+15 / 11>0$. Under small uncertainty, player $i$ is able to affect $P$ only by contributing more than 10 units. This implies facing higher marginal contribution costs; nevertheless, marginal payoffs of contributing more than 10 units while affecting $P$ is $-0.45+$ $15 /(b-a+1)$, which is positive under both large and small uncertainty. It follows that, under both large and small uncertainty, either $q_{i}\left(q_{-i}^{\min }\right)=0$ or $q_{i}\left(q_{-i}^{\min }\right)=\min \left(q_{-i}^{\min }, b\right)$.

In fact, for our parameter values, $q_{i}\left(q_{-i}\right)=\min \left(q_{-i}^{\min }, b\right)$ in both treatments and any $q_{-i}^{\min } \geq a$. For instance, under large uncertainty and $q_{-i}^{\min }=10$, contributing 10 tokens is preferable to contributing nothing since $-0.05 \times 10+$ 
$15 / 11>0$. These best-response patterns thus support symmetric Nash equilibria at all $b-a+1$ integers $q_{i} \in\{a, a+1, \ldots, b-1, b\}$.

In summary, under large uncertainty, there exists a symmetric non-cooperative equilibrium at $q_{i}=0$ and 11 symmetric coordination/cooperation equilibria at $q_{i} \in\{10, \ldots, 20\}$. Under small uncertainty, there is again a symmetric equilibrium at $q_{i}=0$ for all $i$, and also three coordination/cooperation equilibria at $q_{i} \in\{14,15,16\}$. 


\section{Appendix C. Additional tables}

Table C1. Probability of reaching threshold

\begin{tabular}{lcccccc}
\hline & \multicolumn{3}{c}{ Summation } & & Weakest link \\
\hline & Certainty & Uncertainty & $\begin{array}{c}\text { Small } \\
\text { uncert. }\end{array}$ & Certainty & Uncertainty & $\begin{array}{c}\text { Small } \\
\text { uncert. }\end{array}$ \\
\cline { 2 - 7 } $\begin{array}{l}P=1 \text { (certain } \\
\text { avoidance) }\end{array}$ & $60 \%$ & $0 \%$ & $50 \%$ & $90 \%$ & $0 \%$ & $37.5 \%$ \\
$0.5 \leq P<1$ & $0 \%$ & $70 \%$ & $30 \%$ & $0 \%$ & $10 \%$ & $0 \%$ \\
$0<P<0.5$ & $0 \%$ & $30 \%$ & $10 \%$ & $0 \%$ & $50 \%$ & $25 \%$ \\
$P=0$ (certain loss) & $40 \%$ & $0 \%$ & $10 \%$ & $10 \%$ & $40 \%$ & $37.5 \%$ \\
\hline Mean & 0.6 & 0.5 & 0.74 & 0.9 & 0.15 & 0.46
\end{tabular}

Table C2. Descriptive statistics: contributions in both rounds, pledges, and suggested group contribution (per person)

\begin{tabular}{|c|c|c|c|c|c|}
\hline & & $\begin{array}{l}\text { Contribution } \\
\text { Round } 1\end{array}$ & $\begin{array}{l}\text { Contribution } \\
\text { Round } 2\end{array}$ & $\begin{array}{l}\text { Pledge } \\
\text { Round } 2\end{array}$ & $\begin{array}{c}\text { Suggested group } \\
\text { behavior } \\
\text { (per person) }\end{array}$ \\
\hline & & $\begin{array}{l}\text { Mean } \\
\text { (s.d.) } \\
\text { Mode }\end{array}$ & $\begin{array}{l}\text { Mean } \\
\text { (s.d.) } \\
\text { Mode }\end{array}$ & $\begin{array}{l}\text { Mean } \\
\text { (s.d.) } \\
\text { Mode }\end{array}$ & $\begin{array}{l}\text { Mean } \\
\text { (s.d.) } \\
\text { Mode }\end{array}$ \\
\hline Summation: & Certainty & $\begin{array}{c}13.74 \\
(4.7) \\
15\end{array}$ & $\begin{array}{c}14.8 \\
(4.0) \\
15\end{array}$ & $\begin{array}{c}14.5 \\
(4.1) \\
15\end{array}$ & $\begin{array}{c}14.1 \\
(4.69) \\
15\end{array}$ \\
\hline & Uncertainty & $\begin{array}{c}13.68 \\
(5.56) \\
20\end{array}$ & $\begin{array}{c}14.9 \\
(5.0) \\
20\end{array}$ & $\begin{array}{c}15.7 \\
(4.8) \\
20\end{array}$ & $\begin{array}{c}14.85 \\
(6.08) \\
20\end{array}$ \\
\hline & $\begin{array}{l}\text { Small } \\
\text { uncertainty }\end{array}$ & $\begin{array}{c}14.32 \\
(4.55) \\
16 \\
\end{array}$ & $\begin{array}{c}15.5 \\
(3.9) \\
16\end{array}$ & $\begin{array}{c}14.9 \\
(4.4) \\
16\end{array}$ & $\begin{array}{c}14.68 \\
(4.79) \\
16 \\
\end{array}$ \\
\hline $\begin{array}{l}\text { Weakest } \\
\text { link: }\end{array}$ & $\begin{array}{l}\text { Small } \\
\text { uncertainty }\end{array}$ & $\begin{array}{c}14.51 \\
(3.82) \\
15 \\
15.02 \\
(4.81) \\
15 \\
14.62 \\
(2.9) \\
16\end{array}$ & $\begin{array}{c}15.7 \\
(1.7) \\
15 \\
15.5 \\
(4.5) \\
15 \\
15.6 \\
(3.3) \\
16\end{array}$ & $\begin{array}{c}15.8 \\
(1.8) \\
15 \\
16.06 \\
(4.2) \\
20 \\
16.1 \\
(2.2) \\
16\end{array}$ & $\begin{array}{c}15.8 \\
(2.06) \\
15 \\
16.0 \\
(4.2) \\
20 \\
16.1 \\
(2.0) \\
16\end{array}$ \\
\hline
\end{tabular}


Table C3. Tobit regression model, individual contributions to the public good. Marginal effects evaluated at sample mean, standard errors clustered at group level

\begin{tabular}{lll}
\hline & Summation & Weakest link \\
\hline Uncertainty & 0.538 & 0.013 \\
& $(0.982)$ & $(0.819)$ \\
Small uncertainty & 0.891 & -0.298 \\
& $(0.669)$ & $(0584)$ \\
Constant & $15.08^{* *}$ & $15.91^{* * *}$ \\
& $(0.313)$ & \\
\hline$N$ & 300 & 280 \\
\hline
\end{tabular}

Table C4. Probability of reaching threshold, observed and simulated, experiment without pledges

\begin{tabular}{lcccccc}
\hline & \multicolumn{3}{c}{ Summation } & \multicolumn{2}{c}{ Weakest link } \\
\cline { 2 - 6 } & Certainty & Uncertainty & $\begin{array}{c}\text { Small } \\
\text { uncert }\end{array}$ & Certainty & Uncertainty & $\begin{array}{c}\text { Small } \\
\text { uncert. }\end{array}$ \\
\cline { 2 - 7 } & \multicolumn{7}{c}{ Observed } \\
\hline$P=1$ (certain avoidance) & $30 \%$ & $0 \%$ & $0 \%$ & $30 \%$ & $0 \%$ & $12.5 \%$ \\
$0.5 \leq P<1$ & $0 \%$ & $10 \%$ & $40 \%$ & $0 \%$ & $0 \%$ & $12.50 \%$ \\
$0<P<0.5$ & $0 \%$ & $90 \%$ & $30 \%$ & $0 \%$ & $20 \%$ & $0 \%$ \\
$P=0$ (certain loss) & $70 \%$ & $0 \%$ & $20 \%$ & $70 \%$ & $80 \%$ & $75 \%$ \\
\hline Mean & 0.30 & 0.37 & 0.40 & 0.30 & 0.02 & 0.21 \\
\hline$P=1$ (certain avoidance) & $20 \%$ & $0 \%$ & $10 \%$ & $32 \%$ & $0 \%$ & $6 \%$ \\
$0.5 \leq P<1$ & $0 \%$ & $25 \%$ & $23 \%$ & $0 \%$ & $6 \%$ & $20 \%$ \\
$0<P<0.5$ & $0 \%$ & $73 \%$ & $28 \%$ & $0 \%$ & $29 \%$ & $9 \%$ \\
$P=0$ (certain loss) & $80 \%$ & $2 \%$ & $39 \%$ & $68 \%$ & $65 \%$ & $66 \%$ \\
\hline Mean & 0.20 & 0.37 & 0.34 & 0.32 & 0.10 & 0.22 \\
\hline
\end{tabular}


Table C5. Relation between pledges and contributions in round 2. Mean, minimum, and standard deviation at group level (p-values based on Wilcoxon sign rank)

\begin{tabular}{|c|c|c|c|c|c|}
\hline & & & Pledge & Contribution & $\mathrm{p}$-value \\
\hline \multirow[t]{9}{*}{ Summation } & \multirow[t]{3}{*}{ Certainty } & Mean & 14.50 & 14.84 & 0.838 \\
\hline & & Min & 8.70 & 6.8 & 0.304 \\
\hline & & Std & 3.52 & 3.60 & 0.879 \\
\hline & \multirow[t]{3}{*}{ Uncertainty } & Mean & 15.70 & 14.95 & 0.201 \\
\hline & & Min & 6 & 4.5 & 0.474 \\
\hline & & Std & 4.80 & 4.62 & 0.575 \\
\hline & \multirow[t]{3}{*}{ Small Uncertainty } & Mean & 14.93 & 15.52 & 0.333 \\
\hline & & Min & 6.1 & 7.9 & 0.719 \\
\hline & & Std & 4.14 & 3.43 & 0.241 \\
\hline \multirow[t]{9}{*}{ Weakest link } & \multirow[t]{3}{*}{ Certainty } & Mean & 15.8 & 15.73 & 0.385 \\
\hline & & Min & 14.5 & 14.5 & 1.000 \\
\hline & & Std & 1.66 & 1.55 & 0.414 \\
\hline & \multirow[t]{3}{*}{ Uncertainty } & Mean & 16.06 & 15.48 & 0.575 \\
\hline & & Min & 7.8 & 7 & 0.678 \\
\hline & & Std & 4.01 & 3.89 & 0.721 \\
\hline & \multirow[t]{3}{*}{ Small Uncertainty } & Mean & 16.11 & 15.55 & 0.360 \\
\hline & & Min & 13.25 & 10.75 & 0.722 \\
\hline & & Std & 1.80 & 2.38 & 0.674 \\
\hline
\end{tabular}

Table C6. Relation between contributions in round 1 and pledges in round 2, comparison at the individual level (p-values based on Wilcoxon sign rank)

\begin{tabular}{llccc}
\hline & Certainty & $\begin{array}{c}\text { Contribution } \\
\text { round 1 }\end{array}$ & $\begin{array}{c}\text { Pledge } \\
\text { round 2 }\end{array}$ & p-value \\
\hline Summation & $\begin{array}{c}13.74 \\
(4.7)\end{array}$ & $\begin{array}{c}14.5 \\
(4.1)\end{array}$ & 0.064 \\
& Uncertainty & 13.68 & 15.7 & 0.000 \\
& Small & $(5.56)$ & $(4.8)$ & \\
& uncertainty & 14.32 & 14.9 & 0.028 \\
& Certainty & $(4.55)$ & $(4.4)$ & \\
& Uncertainty & $(3.82)$ & $(1.8)$ & \\
& Small & 15.02 & 16.06 & 0.001 \\
& uncertainty & $(4.81)$ & $(4.2)$ & \\
& & $(2.9)$ & 16.1 & 0.0001 \\
& & & & \\
\hline
\end{tabular}


Table C7. Individual characteristics across treatments, standard deviations in parentheses

\begin{tabular}{|c|c|c|c|c|c|c|}
\hline & $\begin{array}{c}\text { Summation, } \\
\text { certainty }\end{array}$ & $\begin{array}{c}\text { Summation, } \\
\text { uncertaint }\end{array}$ & $\begin{array}{c}\text { Summation, small } \\
\text { uncertainty }\end{array}$ & $\begin{array}{c}\text { Weakest link, } \\
\text { certainty }\end{array}$ & $\begin{array}{c}\text { Weakest link, } \\
\text { uncertainty }\end{array}$ & $\begin{array}{l}\text { Weakest link, } \\
\text { small uncert }\end{array}$ \\
\hline \multirow[t]{2}{*}{ Risk measure } & 5.55 & 5.80 & 5.36 & 5.52 & 5.51 & 5.90 \\
\hline & $(2.12)$ & $(2.13)$ & $(2.08)$ & $(2.05)$ & $(2.28)$ & $(1.81)$ \\
\hline \multirow[t]{2}{*}{ Time preference } & 7.36 & 7.54 & 7.45 & 7.35 & 7.30 & 7.20 \\
\hline & $(2.00)$ & $(2.12)$ & $(2.01)$ & $(1.90)$ & $(2.34)$ & $(2.14)$ \\
\hline \multirow[t]{2}{*}{ Generosity } & 7.44 & 7.46 & 7.27 & 7.45 & 6.82 & 7.13 \\
\hline & $(2.04)$ & $(2.11)$ & (1.98) & $(2.14)$ & $(2.40)$ & $(2.18)$ \\
\hline \multirow[t]{2}{*}{ Punish you } & 5.37 & 5.35 & 4.96 & 4.95 & 5.32 & 5.46 \\
\hline & $(2.70)$ & $(2.55)$ & $(2.56)$ & $(2.56)$ & $(2.77)$ & $(2.70)$ \\
\hline \multirow[t]{2}{*}{ Punish others } & 5.57 & 5.71 & 5.57 & 5.85 & 5.65 & 5.55 \\
\hline & $(2.38)$ & $(2.52)$ & $(2.39)$ & $(2.37)$ & $(2.42)$ & $(2.27)$ \\
\hline \multirow[t]{2}{*}{ Trust } & 1.74 & 1.57 & 1.76 & 2.19 & 1.78 & 1.98 \\
\hline & $(0.77)$ & $(0.81)$ & $(0.64)$ & $(0.68)$ & $(0.84)$ & $(0.80)$ \\
\hline \multirow[t]{2}{*}{ Female } & 0.55 & 0.64 & 0.60 & 0.58 & 0.55 & 0.56 \\
\hline & $(0.50)$ & $(0.48)$ & $(0.49)$ & $(0.50)$ & $(0.50)$ & $(0.50)$ \\
\hline \multirow[t]{2}{*}{ Age } & 28.51 & 27.85 & 27.50 & 27.79 & 27.11 & 26.80 \\
\hline & $(9.07)$ & $(5.57)$ & $(4.91)$ & $(6.65)$ & $(5.23)$ & $(4.73)$ \\
\hline \multirow[t]{2}{*}{ Econ } & 0.28 & 0.22 & 0.27 & 0.20 & 0.26 & 0.33 \\
\hline & $(0.45)$ & $(0.42)$ & $(0.45)$ & $(0.40)$ & $(0.44)$ & $(0.47)$ \\
\hline Observations & 100 & 100 & 100 & 100 & 100 & 80 \\
\hline
\end{tabular}

Note: Risk measures: Response to the question "Please tell me, in general, how willing or unwilling you are to take risks. Please use a scale from 0 to 10, where 0 means you are completely unwilling to take risks and 10 means you are very willing to take risks. Time preference: Response to question "How willing are you to give up something that is beneficial for you today, in order to benefit more from it in the future?" Generosity: Response to question "How willing are you to give to good causes without expecting anything in return?" Punish you: Response to question "How willing are you to punish someone who treats you unfairly, even if there may be costs for you? Punish others: Response to question "How willing are you to punish someone who treats others unfairly, even if there may be costs for you?" For these four questions, 0 means completely unwilling to do so and 10 means very willing to do so. Trust: Response to the question "Did you trust the other players to make the contributions they pledged?", where 0 means 
very much and 3 means not at all. Female: Dummy variable equal to one if female subject. Age in years. Econ: Dummy variable equal to one if majoring in economics or business. 